\title{
A subset of activated fibroblasts is associated with distant relapse in early luminal breast cancer
}

Claire Bonneau ${ }^{1,2,3}$, Antoine Eliès ${ }^{1,2,3 \dagger}$, Yann Kieffer ${ }^{1,2+}$, Brigitte Bourachot ${ }^{1,2+}$, Sylvain Ladoire ${ }^{4}$, Floriane Pelon ${ }^{1,2}$, Delphine Hequet ${ }^{3}$, Jean-Marc Guinebretière ${ }^{5}$, Christophe Blanchet ${ }^{4}$, Anne Vincent-Salomon ${ }^{6}$, Roman Rouzier ${ }^{3,7,8}$ and Fatima Mechta-Grigoriou ${ }^{1,2^{*}}$

\begin{abstract}
Background: Early luminal breast cancer (BC) represents $70 \%$ of newly diagnosed BC cases. Among them, small (under $2 \mathrm{~cm}$ ) BC without lymph node metastasis (classified as T1N0) have been rarely studied, as their prognosis is generally favorable. Nevertheless, up to 5\% of luminal T1NO BC patients relapse with distant metastases that ultimately prove fatal. The aim of our work was to identify the mechanisms involved in metastatic recurrence in these patients.

Methods: Our study addresses the role that autonomous and non-autonomous tumor cell features play with regard to distant recurrence in early luminal BC patients. We created a cohort of T1NO luminal BC patients (tumors between $0.5-2 \mathrm{~cm}$ without lymph node metastasis) with metastatic recurrence ("cases") and corresponding "controls" (without relapse) matched 1:1 on main prognostic factors: age, grade, and proliferation. We deciphered different characteristics of cancer cells and their tumor micro-environment (TME) by deep analyses using immunohistochemistry. We performed in vitro functional assays and highlighted a new mechanism of cooperation between cancer cells and one particular subset of cancer-associated fibroblasts (CAF).

Results: We found that specific TME features are indicative of relapse in early luminal BC. Indeed, quantitative histological analyses reveal that "cases" are characterized by significant accumulation of a particular CAF subset (CAF-S1) and decrease in CD4 ${ }^{+} \mathrm{T}$ lymphocytes, without any other association with immune cells. In multivariate analysis, TME features, in particular CAF-S1 enrichment, remain significantly associated with recurrence, thereby demonstrating their clinical relevance. Finally, by performing functional analyses, we demonstrated that CAF-S1 prometastatic activity is mediated by the $\mathrm{CDH} 11$ /osteoblast cadherin, consistent with bones being a major site of metastases in luminal BC patients.

(Continued on next page)
\end{abstract}

\footnotetext{
* Correspondence: fatima.mechta-grigoriou@curie.fr

${ }^{\dagger}$ Antoine Eliès, Yann Kieffer and Brigitte Bourachot contributed equally to this work.

'Stress and Cancer Laboratory, Equipe labelisée Ligue Nationale Contre le Cancer, Institut Curie, PSL Research University, 26, rue d'Ulm, F-75005 Paris, France

${ }^{2}$ Inserm U830, Institut Curie, PSL Research University, 26, rue d'Ulm, F-75005

Paris, France

Full list of author information is available at the end of the article
}

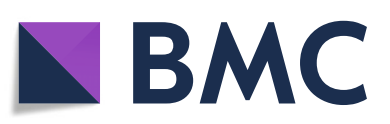

(c) The Author(s). 2020 Open Access This article is licensed under a Creative Commons Attribution 4.0 International License, which permits use, sharing, adaptation, distribution and reproduction in any medium or format, as long as you give appropriate credit to the original author(s) and the source, provide a link to the Creative Commons licence, and indicate if changes were made. The images or other third party material in this article are included in the article's Creative Commons licence, unless indicated otherwise in a credit line to the material. If material is not included in the article's Creative Commons licence and your intended use is not permitted by statutory regulation or exceeds the permitted use, you will need to obtain permission directly from the copyright holder. To view a copy of this licence, visit http://creativecommons.org/licenses/by/4.0/ The Creative Commons Public Domain Dedication waiver (http://creativecommons.org/publicdomain/zero/1.0/) applies to the data made available in this article, unless otherwise stated in a credit line to the data. 
(Continued from previous page)

Conclusions: This study shows that distant recurrence in T1N0 BC is strongly associated with the presence of CAF-

S1 fibroblasts. Moreover, we identify CDH11 as a key player in CAF-S1-mediated pro-metastatic activity. This is independent of tumor cells and represents a new prognostic factor. These results could assist clinicians in identifying luminal BC patients with high risk of relapse. Targeted therapies against CAF-S1 using anti-FAP antibody or CDH11-targeting compounds might help in preventing relapse for such patients with activated stroma.

Keywords: Luminal breast cancer, Metastases, Cancer-associated fibroblasts, Stroma, CDH11, Cadherin 11, Tumor infiltrating lymphocytes, TILs, Tumor micro-environment

\section{Background}

Breast cancer $(\mathrm{BC})$ is the most frequent cancer in women with an estimated 2.08 million new cancer cases diagnosed in 2018 (24.2\% of all female cancers) [1]. BC is a heterogeneous disease with various prognoses. Among the four main BC subtypes (luminal A, luminal $\mathrm{B}$, basal-like and human epidermal growth factor receptor 2 (HER2)-enriched [2-4]), luminal BC express hormonal receptors and are considered sensitive to endocrine therapy. They represent $70 \%$ of all $\mathrm{BC}$ and almost $85 \%$ of early $\mathrm{BC}$ [5-7]. The prognosis for early luminal BC patients is very good with a disease-free survival rate of $99.1 \%$ at 5 years for luminal T1N0 BC, i.e., small luminal tumors (smaller or equal to $2 \mathrm{~cm}$ ) without lymph node metastasis [8]. Despite this overall good prognosis, up to $5 \%$ of patients relapse, even sometimes belatedly, and die from metastatic disease. Thus, the balance between overtreating most patients who will not relapse, and undertreating patients who will ultimately relapse, remains a challenging clinical problem [911]. Hence, only a few comprehensive studies have been published on luminal T1N0 BC. On the whole, high proliferation index (histological grade or Ki67), young age at diagnosis, progesterone receptor (PR) expression, and lymphovascular invasion are known prognostic factors in this subgroup of patients [10]. More recently, commercial classifications have been developed as prognostic and/or predictive tools. For example, the Prosigna ${ }^{\mathrm{m}}$ test combines tumor size, lymph node status, and the transcriptomic PAM50 gene signature (as defined in [12]) to provide the molecular $\mathrm{BC}$ subtype, an individualized prognostic score called "ROR score" (risk of recurrence score) for predicting metastasis-free survival at 10 years $[13,14]$. In a study focusing on T1N0 $\mathrm{ER}^{+} / \mathrm{HER}^{-} \mathrm{BC}$, the ROR score was a better prognostic tool than histological grade and Ki67 [14]. Other studies have indicated that the ROR score is superior to a standardized immunohistochemical classification, but they did not focus on luminal T1N0 BC $[13,15]$. It is important to note that until now there is no biological or translational study focusing on T1N0 luminal BC. Subsequently, there exists a real need for new strategies to determine the long term prognosis of these patients.
It is now well established that tumor microenvironment (TME) plays a key role in tumor development and progression. In addition to cancer cells themselves, various normal cells, such as cancer-associated fibroblasts (CAF), immune and endothelial cells, and pericytes, are embedded in the extracellular matrix (ECM) and are all involved in numerous phases of tumor growth and spread. Indeed, there is now long-established evidence for the role of vascular density, as well as innate and adaptive immunity, in tumorigenesis. Carcinomaassociated fibroblasts (CAF) constitute one of the most abundant stromal components in solid tumors [16-20]. Although CAF heterogeneity has been largely underestimated in the past, several recent studies have identified several CAF subsets [21-24]. In particular, the concomitant analysis of several stromal markers, including fibroblast activation protein (FAP), smooth-muscle $\alpha$ actin (SMA), and integrin $\beta 1$ (CD29), demonstrated the existence of at least 4 different CAF sub-populations (named CAF-S1 to CAF-S4) in human BC $[22,23]$. CAF-S1 $\left(\mathrm{FAP}^{\mathrm{Hi}} \mathrm{CD} 29^{\mathrm{Med}} \alpha \mathrm{SMA}^{\mathrm{Hi}} \mathrm{PDGFR}^{\mathrm{Med}-\mathrm{Hi}} \mathrm{FSP}^{\text {Low-Hi }}\right.$ ) and CAF-S4 (FAP ${ }^{\text {Neg-Low }}$ CD29 ${ }^{\mathrm{Hi}} \alpha \mathrm{SMA}^{\mathrm{Hi}}$ PDGF $R \beta^{\text {Low-Med }}$ FSP $1^{\text {Low-Med }}$ ) are myofibroblasts that accumulate mainly in aggressive $\mathrm{BC}$, i.e., HER2 and triplenegative (TN) BC $[22,23]$. Both subpopulations defined either by ECM (CAF-S1) or perivascular/contractile (CAF-S4) signatures have been validated in other studies in distinct adenocarcinomas, as well as in mouse models [21, 24-29]. In addition, the first single cell data from human and mouse cancers confirmed the existence of these two myofibroblastic CAF subsets [30-32]. The two other CAF subpopulations, CAF-S2 (FAP ${ }^{\text {Neg }}$ CD29 ${ }^{\text {Low }}$ $\alpha \mathrm{SMA}^{\mathrm{Neg}}$ PDGFR $^{\mathrm{Neg}} \mathrm{FSP}^{\text {Neg-Low }}$ ) and CAF-S3 (FAP-

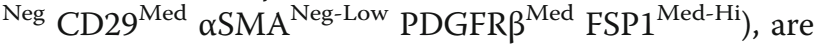
detected in tumors but also in healthy tissues, suggesting that they could be normal-like resident fibroblasts. Taken as a whole, these observations show that both CAF-S1 and CAF-S4 can be detected in distinct cancer types and species, thereby highlighting their relevance in cancer research. Interestingly, the CAF-S1 subset exhibits immunosuppressive properties by attracting CD4+ CD25+ T lymphocytes, increasing their survival, enhancing their differentiation in regulatory $\mathrm{T}$ cells, and 
promoting their activity [22]. These data were previously confirmed in human BC observations inferred from pancreatic cancer mouse models and derived organoids [21-24, 33]. Finally, although CAF-S2 are mostly detected in luminal patients, some luminal patients accumulate either CAF-S1 or CAF-S4, suggesting that these patients could show distinct clinical features. Based on the lack of knowledge relating to relapse in luminal $\mathrm{BC}$, the objective of the current study was to decipher the mechanisms involved in distant recurrence of early luminal BC. We investigated cancer cell-autonomous roles, together with the impact of TME, and took into account adaptive immunity, vascularization, and CAF subsets.

\section{Methods}

\section{Patient cohort}

Patient data were selected from the Institut Curie Hospital Group (IC) BC database. 57,665 patients with in situ or invasive BC treated at IC, at the Paris or SaintCloud sites (France), from 1980 to 2010 were considered for this case-control study. We selected 3739 female patients with unifocal invasive BC, T1b, or T1c NOM0, expressing estrogen receptor $(\mathrm{ER} \geq 10 \%)$ without overexpression of HER2 (HER2 0, 1+, or 2+ without gene amplification in in situ hybridization, as defined by the American Society of Clinical Oncology/College of American Pathologists Clinical practice guidelines [34]). Patients had been treated at IC by primary surgery between 2003 and 2010 (see flow chart in Additional File 1: Fig. S1). Among this population, there were 52 patients with distant relapse (excluding local, contralateral, or axillary lymph node relapse)-then called "cases"-and available samples (Additional File 1: Fig. S1). We chose 52 patient" controls" from the same population with a 1 : 1 match in age, grade, and Ki67. Clinical, pathologic, and therapeutic characteristics of the cohort studied in this paper are described in Table 1.

\section{Ethics}

All patients included in our study and treated at IC were informed by their referring oncologist that their biological samples could be used for research purposes. All patients signed informed consent of non-opposition for the collection of excessive tumor samples and molecular analysis. The projects developed here are based on surgical residues, available after histopathological analyses, and not required for diagnosis. There is no interference with clinical practice. Human experimental procedures for TME studies driven in Dr. F. Mechta-Grigoriou's laboratory were approved by the Institutional Review Board and Ethics committee of the Institut Curie Hospital group (approval February 12, 2014) and CNIL
(Commission Nationale de l'informatique et des Libertés) ( $\mathrm{N}^{\circ}$ approval: 1674356 delivered March 30, 2013).

\section{Immunohistochemistry}

Patient samples were obtained from the Department of Pathology at IC. A pathologist selected a representative sample for each tumor. For the different staining performed in this study, the embedded tissues were sectioned with a maximum delay of 3 months. For each set of experiments (CAF subsets, immune and cancer cells), consecutive sections of paraffin-embedded $\mathrm{BC}$ tissues $(3 \mu \mathrm{m})$ were performed and then stored in a cold room. Sections were promptly stained using a streptavidinperoxidase protocol (Vectastain $\mathrm{ABC}$ kit; Vector Labs \#PK-4000, or Dako EnVision Flex HRP \#DM822) on Autostainer Labvision (Thermoscientific, NLVE-LV1.30463) and Benchmark apparatus (Ventana) for staining of CAF and immune cells respectively. In brief, paraffinembedded sections were incubated with specific antibodies (Additional File 2: Table S1 for antibody references and conditions) recognizing CAF subsets-FAP (fibroblast activation protein $\alpha 1$ ), $\alpha$ SMA (smooth muscle $\alpha$-actin), integrin $\beta 1 / \mathrm{CD} 29, \mathrm{~S} 100-\mathrm{A} 4 / \mathrm{FSP} 1$ (fibroblastspecific protein 1), and PDGFR $\beta$ (platelet-derived growth factor receptor- $\beta$ )-and lymphocytes (CD4, CD8, FOXP3, IL17, T-Bet, CD20), dendritic cells (DC LAMP), macrophages (CD163), PD-1, PD-L1, CD31, and CDH11. Incubation took place in Dako Wash Buffer (Dako, \#GC807) for $1 \mathrm{~h}$ at room temperature following unmasking in either Tris/EDTA buffer, $\mathrm{pH}=9$ (Dako \#S2367), or citrate buffer, pH $=6$ (Dako \#S2369) (depending on the primary antibody, Additional File 2: Table S1). Unmasking was carried out in a microwave for $20 \mathrm{~min}$ at $97^{\circ} \mathrm{C}$.

\section{Pathological and immunostaining analyses}

All pathological analyses were performed after scanning slides with the Philips Ultra-Fast Scanner 1.6 RA, except for the immunological slides that were numerized with Nanozoomer HT2.0 (Hammamatsu) at $\times 20$ magnification. Those analyses were performed blinded for clinicopathologic data. The percentage of stroma was evaluated on H\&E (hematoxylin and eosin) sections. For microenvironment analysis, only the intra-tumoral stroma was considered. The adiposity of the stroma was evaluated using a semi-quantitative scoring: 0 when the adipose content of the stroma was less than $1 \%$ of the surface, 1 between 1 and 10\%, 2 between 11 and 30\%, and 3 if superior to $30 \%$.

For staining of each CAF marker, CDH11 and Ecadherin (CDH1), histological scoring (H score) was performed considering all tumor fields observed on sections and given as a function of percentage of stained cells (considering fibroblasts for CAF markers, cancer cells 
Table 1 Patients characteristics

\begin{tabular}{|c|c|c|c|c|}
\hline & Global population $(\boldsymbol{n}=104)$ & Controls $(\boldsymbol{n}=52)$ & Cases $(\boldsymbol{n}=52)$ & $\boldsymbol{p}$ value \\
\hline Age at diagnosis & $55[32 ; 86]$ & $55.5[32 ; 86]$ & $54.5[38 ; 82]$ & $0.77^{\mathrm{a}}$ \\
\hline BMI $\left(k g / m^{2}\right)$ & $23.9[17.3 ; 44.1]$ & $24.1[17.3 ; 44.1]$ & $23.8[19.1 ; 41.6]$ & $0.96^{\mathrm{a}}$ \\
\hline Tumor size (in mm) & $15[6 ; 20]$ & $15[6 ; 20]$ & $15[10 ; 20]$ & $0.59^{\mathrm{a}}$ \\
\hline T1b & 11 (10.6\%) & $5(9.6 \%)$ & $6(11.5 \%)$ & $1^{\mathrm{b}}$ \\
\hline T1c & 93 (89.4\%) & 47 (90.4\%) & $46(88.5 \%)$ & \\
\hline Histological subtype & & & & $0.29^{b}$ \\
\hline N.S.T. & 87 (83.6\%) & $42(80.8 \%)$ & $45(86.5 \%)$ & \\
\hline Lobular & $11(10.6 \%)$ & $8(15.4 \%)$ & $3(5.8 \%)$ & \\
\hline Mixed & $1(1 \%)$ & 0 & $1(1.9 \%)$ & \\
\hline Other & $5(4.8 \%)$ & $2(3.8 \%)$ & $3(5.8 \%)$ & \\
\hline Grade & & & & $0.86^{\mathrm{b}}$ \\
\hline I & $23(22.1 \%)$ & $12(23.1 \%)$ & $11(21.2 \%)$ & \\
\hline$\|$ & $57(54.8 \%)$ & $27(51.9 \%)$ & $30(57.6 \%)$ & \\
\hline III & $24(23.1 \%)$ & $13(25 \%)$ & $11(21.2 \%)$ & \\
\hline Neoplastic emboli & $33(35.1 \%)$ & $14(31.1 \%)$ & 19 (38.8\%) & $0.51^{b}$ \\
\hline Intraductal carcinoma & 75 (72.1\%) & $35(67.3 \%)$ & $40(76.9 \%)$ & $0.38^{\mathrm{b}}$ \\
\hline ER (\%) & $80[14 ; 100]$ & $80[20 ; 100]$ & $85[14 ; 100]$ & $0.64^{a}$ \\
\hline PR (\%) & $60[0 ; 100]$ & $65[0 ; 100]$ & $60[0 ; 100]$ & $0.33^{a}$ \\
\hline HER2 score & & & & $0.90^{\mathrm{b}}$ \\
\hline 0 & $73(70.2 \%)$ & $36(69.2 \%)$ & $37(71.2 \%)$ & \\
\hline+ & $22(21.2 \%)$ & $12(23.1 \%)$ & $10(19.2 \%)$ & \\
\hline$++\mathrm{ISH}-$ & $9(8.7 \%)$ & $4(7.7 \%)$ & $5(9.6 \%)$ & \\
\hline Ki67 (\%) & $19[1 ; 70]$ & $21[1 ; 60]$ & $16.5[5 ; 70]$ & $0.65^{a}$ \\
\hline Mitotic index & $8.5[0 ; 100]$ & $8[0 ; 100]$ & $9.5[1 ; 60]$ & $0.78^{a}$ \\
\hline \multicolumn{5}{|l|}{ Surgical treatment } \\
\hline Lumpectomy & 95 (91.3\%) & $50(96.2 \%)$ & $45(86.5 \%)$ & $0.16^{\mathrm{b}}$ \\
\hline Total mastectomy & $9(8.7 \%)$ & $2(3.8 \%)$ & $7(13.5 \%)$ & \\
\hline Sentinel lymph node biopsy & $53(51 \%)$ & $30(57.7 \%)$ & $23(44.2 \%)$ & $0.23^{b}$ \\
\hline Axillary lymphadenectomy & $51(49 \%)$ & $22(42.3 \%)$ & $29(55.8 \%)$ & \\
\hline \multicolumn{5}{|l|}{ Other treatments } \\
\hline Chemotherapy & $23(22.1 \%)$ & $13(25 \%)$ & $10(19.2 \%)$ & $0.63^{b}$ \\
\hline Radiotherapy & 91 (87.5\%) & 49 (94.2\%) & $42(80.8 \%)$ & $0.07^{b}$ \\
\hline Endocrine therapy & 96 (92.3\%) & $48(92.3 \%)$ & $48(92.3 \%)$ & $1^{b}$ \\
\hline \multicolumn{5}{|l|}{ Evolution } \\
\hline Local relapse & $11(10.6 \%)$ & 0 & $11(21.2 \%)$ & $0.0005^{b}$ \\
\hline Controlateral relapse & $3(2.9 \%)$ & 0 & $3(5.8 \%)$ & $0.24^{b}$ \\
\hline Axillary lymph node relapse & $5(4.8 \%)$ & 0 & $5(9.6 \%)$ & $0.05^{b}$ \\
\hline Distant relapse & $52(50 \%)$ & 0 & 52 (100\%) & \\
\hline Bone metastases & 41 (39.4\%) & 0 & $41(78.8 \%)$ & \\
\hline Visceral metastases & $24(23 \%)$ & 0 & $24(46.2 \%)$ & \\
\hline Death & $31(29.8 \%)$ & 0 & 31 (59.6\%) & $<0.0001^{\mathrm{b}}$ \\
\hline
\end{tabular}

${ }^{a}$ Mann-Whitney test to compare controls and cases

${ }^{b}$ Fisher exact test to compare controls and cases

$B M I$ body mass index, $E R$ estrogen receptor, $P R$ progesterone receptor 
for CDH1 and both CAF and cancer cells analyzed separately for $\mathrm{CDH} 11$ ) multiplied by staining intensity (ranging from 0 to 3 ). The marker level was determined using the median $\mathrm{H}$ score: low if the $\mathrm{H}$ score is inferior to the median and high otherwise. Lobular carcinomas were excluded from CDH1 statistical analyses, as they show constitutive loss of CDH1 expression. Stromal and epithelial compartments were assessed using morphological criteria defined by a clinician. We also used HES and $\mathrm{CDH} 1$ staining to better distinguish epithelial and stromal cells.

Tertiary lymphoid structures per section of tumor were counted on H\&E sections. For quantification of immune infiltrate, at least three fields of $1.65 \mathrm{~mm}^{2}$ per tumor were evaluated ( $\times 10$ magnification). We counted the number of stained immune cells of interest in each compartment (considering the epithelial and stromal compartments separately) and divided by the total area of the observed section. Both stained cells quantification and tumor infiltrating lymphocytes (TILs) on HES stained slides were evaluated according to the International TILs Working Group [35].

For quantification of vascularization, we analyzed eight fields of $1596 \mathrm{~mm}^{2}$ per tumor (× 10 magnification). We used Image J software in order to evaluate the percentage of the surface of the field stained with the CD31 antibody. Each percentage of $\mathrm{CD} 31^{+}$area was normalized on the percentage of stroma in the same photograph. Finally, we expressed results as the mean of the percentage of $\mathrm{CD} 31^{+}$area normalized by the stromal proportion.

\section{Decision tree algorithm for prediction of CAF subset identity}

CAF identity of each tumor was determined using an algorithm developed by the team [22, 23]. In brief, the algorithm takes as input histological scores of CAF markers. Initially, the thresholds (quartiles and median) and the order of decisions were established from FACS data in a prospective cohort of $\mathrm{BC}$ patients, and next transposed to values of IHC data using a learning set of tumors containing both non-activated and activated CAF, as described in [22]. The decision tree algorithm is depicted in Fig. 3g.

\section{Maps of CAF subsets at cellular level}

IHC staining from consecutive sections were scanned on Philips Ultra-Fast Scanner. The $\times 10$ images of CAF markers used in the decision tree algorithm (CD29, FAP, SMA, FSP1) were analyzed from the same areas of representative tumors (considering controls and cases). Images were aligned using elastic transformation from Fiji software plugin (bUnwarpJ). This plugin uses landmarks manually defined on hematoxylin and eosin (H\&E) staining of the sections to compute the optimal correlation between original images and alignment at cellular level by elastic transformation. Images were divided into tiles of $225 \mu \mathrm{m}^{2}$ to mimic the approximate size of one fibroblast, and each tile was annotated according to its position in the section. Aligned and annotated images of the CAF markers were then submitted to color deconvolution, and the intensity of each DAB staining was measured by densitometry analysis using ImageJ software. Each tile was classified into a specific CAF subset using the algorithm developed by the team (see paragraph above), which takes as input DAB intensities of CAF markers measured within each tile. Epithelial tumor cells were masked (represented in gray or black) to better visualize the stromal compartment. Each tile was colored according to classification into CAF-S1 to CAF-S4, using the scheme colors defined throughout the study: CAFS1 red, CAF-S2 orange, CAF-S3 green, and CAF-S4 blue.

\section{Prosigna $^{\mathrm{TM}}$ assay}

We performed a Prosigna ${ }^{\text {tw }}$ test (Prosigna $^{\mathrm{Tm}}$, NanoString Technologies, Seattle, WA, USA) for all samples. We chose the Prosigna $^{\mathrm{Tm}}$ genomic signature because it is the only test to provide $\mathrm{BC}$ molecular subtype, and its longterm prognostic value (risk of distant recurrence) has been clearly validated [14, 36, 37]. For all patients, a breast pathologist identified the invasive tumor area and assessed tumor cellularity on an H\&E section. According to the manufacturer's instructions, depending on the surface area of the tumor a series of $10 \mu \mathrm{m}$ sections were mounted onto Superfrost slides. RNA extraction and nCounter analysis were performed according to the Prosigna $^{\text {TM }}$ instructions, in IC pharmaco-genomic platform. The test failed for 5 patients due to poor RNA quality or insufficient quantity. We obtained results for 99 patients in terms of molecular subtype of BC, ROR score, risk category, and 10-year distant recurrence risk.

\section{RNA sequencing analysis}

We used RNA sequencing from CAF subsets isolated from $\mathrm{BC}$ (data deposited at the European Genome-phenome Archive under accession number EGAS00001002508) [22, 23], in order to examine CDH11 RNA expression.

\section{Human BC cell lines and cell culture conditions}

We used human luminal BC cell lines MCF7 and T47D (from ATCC). Cell line identity has been verified by short tandem repeat (STR) DNA profiling. Cells were grown in DMEM (Gibco \#11995) for MCF7 and RPMI (GE SH30027.01) for T47D with glucose $(4.5 \mathrm{~g} / \mathrm{L}), 4$ $\mathrm{mML}$-glutamine, $1 \mathrm{mM}$ sodium pyruvate supplemented with $10 \%$ fetal bovine serum (FBS) (Biosera \#FB-1003/ 500 ), $1 \%$ penicillin-streptomycin (Gibco \#15140122) in a humidified atmosphere of $20 \% \mathrm{O}_{2}, 5 \%(\mathrm{v} / \mathrm{v}) \mathrm{CO}_{2}$ in air 
at $37^{\circ} \mathrm{C}$. Cells were tested for absence of mycoplasma contamination.

\section{Isolation and culture of human primary CAF-S1 fibroblasts}

Primary CAF-S1 fibroblasts were obtained as described in [38]. Briefly, fresh luminal BC from different patients were received after surgery and sorted by FACS in order to keep only the CAF-S1 subset. CAF-S1 subset was defined in FACS by CD29 ${ }^{\text {Med }} \mathrm{FAP}^{\mathrm{Hi}} \mathrm{FSP}^{\text {Low-Hi }} \alpha S M A^{\mathrm{Hi}}$ PDGFR $\beta^{\text {Med-Hi }}[22]$. After selection, CAF-S1 were plated in 96-well plates and expanded in a pericyte medium (Sciencell Research Laboratories \#1201) with 10\% FBS (Biosera \#FB-1003/500), 1\% penicillin-streptomycin (Gibco \#15140122) in a humidified atmosphere of $1.5 \%$ $\mathrm{O}_{2}, 5 \%(\mathrm{v} / \mathrm{v}) \mathrm{CO}_{2}$ in air at $37^{\circ} \mathrm{C}$. We confirmed by RNA sequencing that, after several passages in culture, CAFS1 primary fibroblasts isolated from $\mathrm{BC}$ patients kept similar molecular identities as those detected without culture [38]. Moreover, we confirmed by FACS that CAF markers at protein levels corroborated data from fresh samples [38]. Functional experiments in co-culture with cancer cells were performed in DMEM with $10 \%$ FBS at $1.5 \% \mathrm{O}_{2}$. For BC cells and primary CAF cell lines, the absence of mycoplasma contamination had been tested and confirmed.

Silencing experiments using small-interfering RNA (siRNA) For small interfering RNA (siRNA) experiments, CAF-S1 primary cultures were transfected with a pool of 4 specific siRNA against CDH11 (Qiagen \#1027416) siCDH11 \#1 SIO2663955 ACC GTC GGA ATT CAT TGT CAA, siCDH11 \#2 SI04434647 CAA GGA CAC TGT GAC CGT CAA, siCDH11 \#3 SIO2663948 CAG AGA GGA TAC ATT TAA TAA, and siCDH11 \#4 SI04434654 CTG AGC TGT AAT TTC GCC TTA-or non-targeting siRNA (siCTR, Qiagen \#1022076, AAT TCT CCG AAC GTG TCA CGT). Transfections were carried out at a final concentration of $20 \mathrm{nM}$ using DharmaFECT 1 transfection reagent (Dharmacon, \#T2001-02) according to manufacturer's instructions. We plated 165,000 cells per well in a six-well plate and performed the transfection $24 \mathrm{~h}$ later.

\section{Immunofluorescence}

The same protocol as this one recently described by the Stress and Cancer's lab headed by Dr. F. MechtaGrigoriou in [38] was used. In brief, 200,000 BC cells in the presence of $200,000 \mathrm{CAF}-\mathrm{S} 1,24 \mathrm{~h}$ post-silencing, were seeded on coverslips in 6-well plates. Forty-eight hours later, cells were fixed in $4 \%$ PFA for $15 \mathrm{~min}$, permeabilized with $0.1 \%$ SDS in PBS for $10 \mathrm{~min}$, blocked in PBS-Tween $0.1 \%$ with 5\% BSA (Euromedex, \#04-100812-C) for $30 \mathrm{~min}$, and incubated with antibodies diluted in PBS-Tween $0.1 \%$ with $5 \%$ BSA overnight at $4{ }^{\circ} \mathrm{C}$. Antibodies were CDH1/E-cadherin (1:300, Cell Signaling Technology, \#3195). Cells were then incubated with Cy3-anti-rabbit secondary (1:500, JacksonImmunoResearch, \#711-165-152) in parallel with Alexa Fluor TM 488 phalloidin (1:200, Invitrogen, \#A12379) for $30 \mathrm{~min}$ at RT in PBS-Tween $0.1 \%$ with $5 \%$ BSA. After several washing steps, coverslips were mounted on slides with a drop of Vectashield mounting medium with DAPI (Vector, \#H-1200). Slides were next examined on an upright Epifluorescence Microscope with Apotome (Zeiss) with a $\times 40$ oil-immersion objective and images were acquired with identical settings using a digital camera (Photometrics CoolSNAP HQ2).

\section{qRT-PCR}

For gene expression analysis, cells were lysed in Qiazol and RNA was isolated using miRNeasy kit (Qiagen, \#217004) and Qiacube, following manufacturer's instructions. One microgram of RNA was used for reversetranscription using random primers (iScript cDNA Synthesis kit; Bio-Rad, \#170-8891). For quantitative RT-PCR (qRT-PCR), the Power SYBR Green PCR Master Mix (Applied Biosystems, \#4367659) and primers at $500 \mathrm{nM}$ (final concentration) were used in a Chromo4 Real-Time PCR detector (Bio-Rad). Primer sequences used for CDH11 are the following: reverse $5^{\prime}$-GGT CTG GAA CCA GTT CTT CG-3' and forward 5'-TCT CGA TCC AAC GTC TTG GT-3'. qRT-PCR were amplified in triplicate for each sample. Expression levels were normalized to cyclophilin $\mathrm{B}$ and represented as fold change compared to the control $\left(2^{\wedge}(-\Delta \Delta \mathrm{Ct})\right)$.

Protein extracts and western blot analysis from cell lines For protein level analyses, CAF-S1 cells were washed with PBS and scraped with Reverse Phase Protein Arra (RPPA) lysis buffer (50 mM Tris pH 6.8, 2\% SDS, 5\% glycerol, $2.5 \mathrm{mM}$ EDTA, $2.5 \mathrm{mM}$ EGTA, $4 \mathrm{mM}$ Na3VO4, $20 \mathrm{mM} \mathrm{NaF}$, and $2 \mathrm{mM}$ dithiothreitol) supplemented with $2 \times$ Halt phosphatase inhibitor (Perbio \#78420) and a complete EDTA-free protease inhibitor cocktail tablet (Roche \#1836170). Samples were boiled for $10 \mathrm{~min}$ at $95^{\circ} \mathrm{C}$. Samples were sonicated in an ice water bath for $15 \mathrm{~min}$, and then centrifuged at $14,000 \mathrm{RPM}$ at $4{ }^{\circ} \mathrm{C}$ for $10 \mathrm{~min}$ to isolate the protein supernatant and eliminate DNA contamination.

The protein concentration was determined using the BCA Assay (Thermo Fisher \#23252); the samples were normalized to a concentration of $1.3 \mathrm{mg} / \mathrm{ml}$, and then denatured for $5 \mathrm{~min}$ at $95^{\circ} \mathrm{C}$. For western blot analysis, $20 \mu \mathrm{g}$ proteins were loaded onto precast $4-12 \%$ Bis-Tris protein gels (Invitrogen) with MOPS SDS (3-(N-morpholino) propanesulfonic acid sodium dodecyl sulfate) as running buffer (ThermoFisher). After electrophoresis, 
the proteins were transferred to a $0.45 \mu \mathrm{m}$ nitrocellulose transfer membrane. Blocking was performed with PBStween and $5 \%$ of BSA during $1 \mathrm{~h}$. Membranes were then blotted overnight at $4{ }^{\circ} \mathrm{C}$ with the appropriate primary antibodies diluted in 5\% of BSA: CDH11 (1:500; R\&D \# MAB1790) and Actin (1:10,000; Sigma \#A5441). Specific binding of antibodies was detected using appropriate peroxidase-conjugated secondary antibodies (Mouse, Jackson ImmunoResearch Laboratories \#115-035-003) and was visualized by enhanced chemiluminescence detection (GE Healthcare Life Science). Densitometric analyses of immunoblots were performed using ImageJ software.

\section{Proliferation and survival assays}

We plated 100,000 CAF-S1 (transfected by siCDH11 or siCTL) with 50,000 MCF7 or 75,000 T47D per well in a six-well plate (Falcon corning \#353046). As a control, cancer cells were plated alone as well. The total number of cells and their survival state were then analyzed by FACS. At 72 and $168 \mathrm{~h}$ post-transfection, attached cells and supernatant of culture were collected, washed in PBS+ solution (PBS, Gibco \#14190; EDTA 2 mM Gibco \#15575; Human Serum 1\%, BioWest \#S4190-100), and centrifuged. Collected cells were next stained with an antibody cocktail containing Brilliant Violet $605^{\mathrm{Tm}}$ antihuman EPCAM (1:50; BioLegend, \#324219) for BC cells and anti-FAP-Pacific Orange (1:200; R\&D Systems, \#MAB3715) for $15 \mathrm{~min}$ at room temperature, EPCAM and FAP staining being used to distinguish CAFs from $\mathrm{BC}$ cells. After a washing step, all samples were resuspended in $50 \mu \mathrm{l}$ of PBS+ containing 1:100 carboxylate beads (Polyscience \#18133) and $5 \mu \mathrm{g} / \mathrm{ml}$ DAPI solution (Thermo Fisher scientific \#D1306). Flow cytometry analyses were performed on LSRFortessa ${ }^{\text {tw }}$ analyzer (BD biosciences). As FACS did not allow the analysis of the entire suspended sample, at least $5 \times 10^{5}$ events were recorded and precision beads were used to normalize viable $\mathrm{BC}$ cell $\left(\mathrm{DAPI}^{-} \mathrm{EPCAM}^{+} \mathrm{FAP}^{-}\right)$and $\mathrm{CAF}\left(\mathrm{DAPI}^{-}\right.$ $\mathrm{EPCAM}^{-} \mathrm{FAP}^{+}$) counts. Compensations were performed using single staining on anti-mouse IgG and negative control beads (BD bioscience \#552843) for each antibody. Data analysis was performed using Flowjo version 10 (LLC, USA). The clustering strategy used was as follows: (i) cells were first gated based on their size (FSCA) and their granulosity (SSC-A) to exclude debris and the number of beads was counted; (ii) cells were then gated on EPCAM and FAP expression to distinguish cancer cells $\left(\mathrm{EPCAM}^{+}, \mathrm{FAP}^{-}\right)$from CAF $\left(\mathrm{EPCAM}^{-}\right.$, $\mathrm{FAP}^{+}$); (iii) finally, the live/dead cells were distinguished by DAPI staining.

\section{Transwell assay}

Eight micrometers of Transwell cell culture inserts (BD Biosciences \#353182) were used for Transwell assays in 12-well plates. According to the condition, BC cells (80, 000 MCF7 or 120,000 T47D) with or without 20,000 CAF-S1 fibroblasts were placed on the upper part of the Transwell device and incubated in $400 \mu \mathrm{l}$ of DMEM supplemented with 1\% FBS for MCF7 and $800 \mu \mathrm{l}$ of RPMI supplemented with 1\% FBS for T47D. The lower chamber either contained $200 \mu \mathrm{l}$ of DMEM supplemented with 1\% FBS alone (control condition) or was plated with 20,000 primary CAF-S1. The experiment was stopped after $24 \mathrm{~h}$ of incubation at $37^{\circ} \mathrm{C}$ in $5 \% \mathrm{CO}_{2}$ and $1.5 \% \mathrm{O}_{2}$. Medium was removed from the upper part of the Transwell device and the membrane in the upper part was washed 3 times with cotton imbibed by PBS. Next, inserts were immersed for $30 \mathrm{~min}$ in $4 \%$ Violet Cristal (sigma \#C0775-100G) and 20\% Ethanol (analaR \#20821.310) for fixation and coloration. Five representative pictures per insert were taken at $\times 5$ magnification. Pictures were then analyzed with ImageJ software. We first performed Transwell assays using only BC cells or only CAF-S1 fibroblasts on the upper chamber. By this way, we confirmed that we could easily distinguish $\mathrm{BC}$ cells from CAF after their migration through the Transwell, according to their respective morphological characteristics. Thus, we considered that upon cocultures BC cells and CAF-S1 displayed different morphologies that enabled us to distinguish them, as shown in Fig. 4 for cancer cells, and Additional File 8: Fig. S6 for CAF.

\section{Statistical analysis}

All statistical analyses and graphs were performed using $\mathrm{R}$ environment (https://cran.r-project.org, version R3.6.2) and RStudio (https://rstudio.com/products/rstudio/download/, version 1.2.5033). Qualitative data (TNM stage, histological subtype, CAF subsets...) were analyzed using the Fisher's exact test. Quantitative data (age, BMI, size of tumor, immune cell content...) were first tested for their normality using the Shapiro test and then analyzed with the pertinent test (Wilcoxon-Mann-Whitney test or Student's $t$ test). Quantitative data were expressed in the manuscript as median (minimal - maximal values). Spearman's correlation test was used to evaluate the correlation coefficient between two parameters. Data shown in this paper are generally represented as boxplots with median, 25th and 75th for the lower and upper hinges, and $1.5 \times$ inter-quartile range from the hinge. Data from in vitro experiments were shown using mean \pm SEM (unless otherwise specified) from at least three independent experiments.

Survival curves were constructed using the KaplanMeyer method implemented in R package survival. Distant progression-free survival was defined as the time between treatment and diagnosis of distant metastasis (excluding local or regional lymph node recurrence). Survival analyses were done according to the Cox model 
with Log-Rank test. Explanatory variables with a $p$ value $<0.20$ in univariate analyses were kept for the multivariate analyses using the Cox model.

Two-sided tests with $p$ value $<0.05$ were considered statistically significant.

\section{Results \\ Establishment of a case-control cohort of luminal breast cancer patients}

In this study, we aimed to define the cancer cellautonomous and non-cancer cell-autonomous mechanisms involved in distant relapse in luminal BC. To do so, we built a cohort of patients from a large group of $57,665 \mathrm{BC}$ patients treated at the Institut Curie (IC) Hospital Group from 1980 to 2010. In order to conduct a case-control study, we first selected 3739 female patients with unifocal invasive BC, T1b, or T1c N0M0, expressing ER without amplification of HER2, and treated by primary surgery between 2003 and 2010 (Additional File 1: Fig. S1). Survival analyses showed that those patients displayed a recurrence rate (Additional File 1: Fig. S1) that was in accordance with the literature [39]. Among these patients, 52 cases of early luminal BC with distant relapse and 52 controls without relapse were selected with a match on age, grade, and Ki67 (Table 1), features described as main prognostic factors for these patients $[9,14]$. In keeping with the paired selection of patients on Ki67 staining (Table 1), we confirmed the absence of difference in tumor cell proliferation between subgroups by using the mitotic index (Table 1). In this cohort of patients, the luminal BC subtype was first determined by ER and HER2 profiling using immunohistochemistry (IHC) (Table 1), as commonly used in clinical practice $[5,6]$. The luminal subtype was next validated in most patients using Prosigna ${ }^{\text {tw }}$ test except for five patients. Using Prosigna $^{\text {Tm }}$ test, four patients (2 cases and 2 controls) were classified in the HER2 subtype and one case was identified as a "basal-like" subtype. This was in accordance with the rate of discordance between IHC and Prosigna ${ }^{\mathrm{Tm}}$ molecular subtype classifications reported in the literature recently [14]. A new independent evaluation of ER, progesterone receptor (PR) and HER2 IHC staining, was thus re-performed for those five patients. Their luminal identity was confirmed, but we noticed a high-proliferation rate: median of 50 mitotic figures evaluated on 10 successive high-magnification fields ( $\min 14, \max 60$ ) and median of $50 \%$ of stained cells by Ki67 ( $\min 20 \%$, max $60 \%$ ). These patients were thus kept in the study as initially defined as luminal subtype by IHC, but we maintained the information in all figures to avoid any potential misinterpretation of the results.

\section{Distant relapse was associated with high ROR score and reduced cancer cell differentiation}

We first investigated the cancer cell properties that might be linked to distant relapse in luminal $\mathrm{BC}$ patients. The ROR score and the risk of recurrence, defined by the Prosigna ${ }^{\text {Tu }}$ test, were higher for cases than controls with a median risk of distant recurrence at 10 years of $10.5 \%$ ( 4 to $30.5 \%$ ) for cases and $7.5 \%$ (2 to 36.5\%) for controls (Fig. 1a, b). Moreover, distant relapse was associated with lower CDH1 (E-cadherin) protein level assessed by histological scoring (Fig. 1c, d). This finding confirmed previous observations [40-42] but, to our knowledge, had not been heretofore shown in the T1N0 luminal BC patient subpopulation. As reduced $\mathrm{CDH} 1$ expression was associated with tumor size, lymph node status, and TNM stage [40-42], we subsequently investigated if $\mathrm{CDH} 1$ histological score ( $\mathrm{H}$ score) was associated with any other clinical parameters. CDH1 H score was significantly anti-correlated with both mitotic index and ROR score $(p=0.001$ and $p=0.0005$ respectively, Spearman test) (Fig. 1e, f). Using multivariate analyses, we showed that reduced $\mathrm{CDH} 1 \mathrm{H}$ score was associated with an increased risk of recurrence, independent of the mitotic index (hazard ratio $(\mathrm{HR})=1.20$; CI95\% [1.01-1.43]; $p=0.03$ ) (Additional File 3: Table S2). In contrast, CDH1 $\mathrm{H}$ score and ROR risk were not independent variables for predicting patient survival (Additional File 3: Table S2), most probably because ROR score is indicative of cancer cell proliferation as well as hormonal signaling and cell differentiation.

\section{Infiltration by $\mathrm{CD}^{+} \mathrm{T}$ lymphocytes is lower in cases than in controls}

Having identified some cancer cell features (such as $\mathrm{CDH} 1 \mathrm{H}$-score and ROR score) associated with distant relapse in luminal $\mathrm{BC}$, we next tested variation in TME composition that could be linked to distant relapse in these patients. We analyzed two main components of the TME (namely immune and stromal cells) and investigated their global content and diversity (including lymphocytes subtypes and CAF subsets). Analyses were performed within the tumor bed regarding the immune infiltration at the surface of either epithelial or stromal cells. We observed that the total number of tumorinfiltrating lymphocytes and tertiary lymphoid structures (TLS) were similar between cases and controls (Fig. 2a, b). Interestingly, there was a lower $\mathrm{CD}^{+} \mathrm{T}$ lymphocyte infiltrate in cases compared to controls: median of 11.2 $\mathrm{CD}_{4}^{+} \mathrm{T}$ lymphocytes per $\mathrm{mm}^{2}(0.2$ to 73.3$)$ for cases and $18.2 \mathrm{CD}^{+} \mathrm{T}$ lymphocytes per $\mathrm{mm}^{2}$ (3.0 to 77.4) for controls (Fig. 2d, e). $\mathrm{CD}^{+} \mathrm{T}$ lymphocyte content was correlated with the CDH1 $\mathrm{H}$ score in cases, while this was not the case in controls (Rho $=0.21, p=0.044$ in the whole cohort; Rho $=0.36, p=0.009$ for cases, $\mathrm{Rho}=-$ 
A

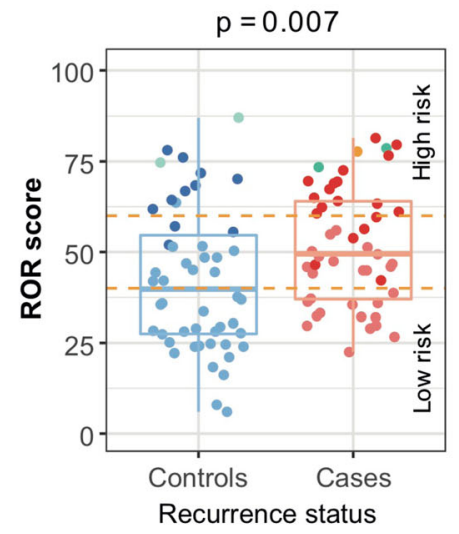

B

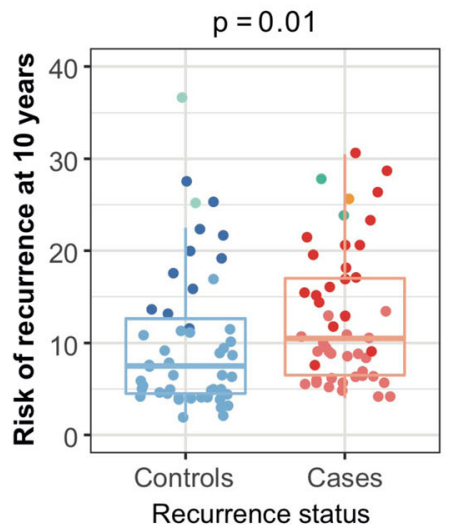

C
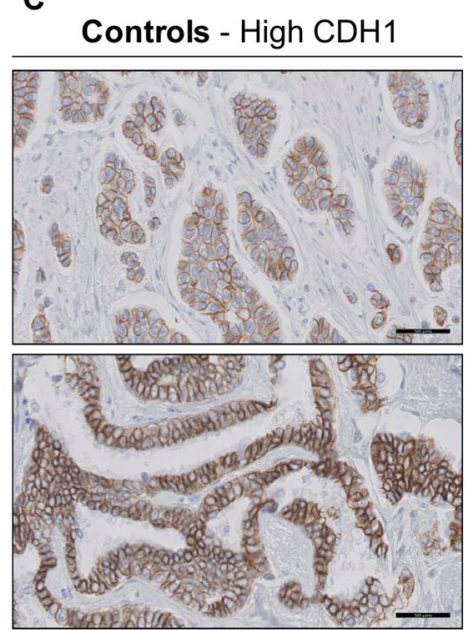

E

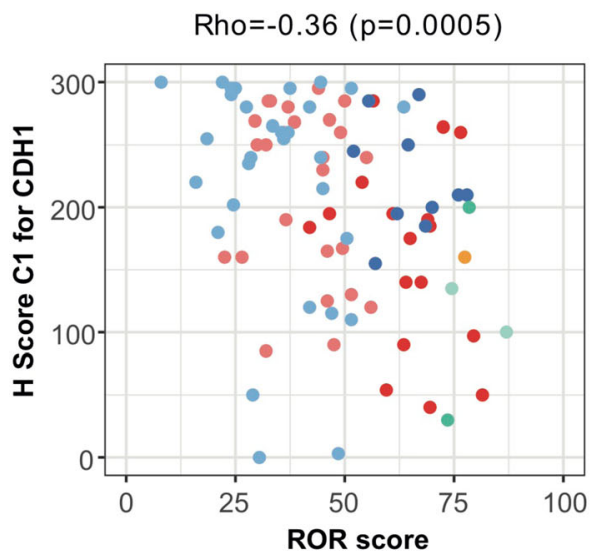

D

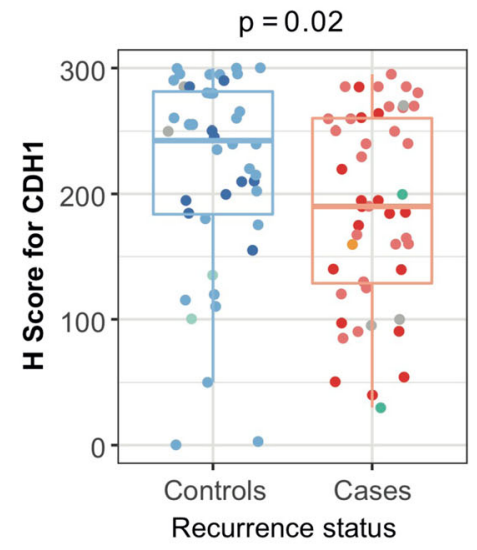

$\mathbf{F}$

Rho $=-0.32(p=0.001)$

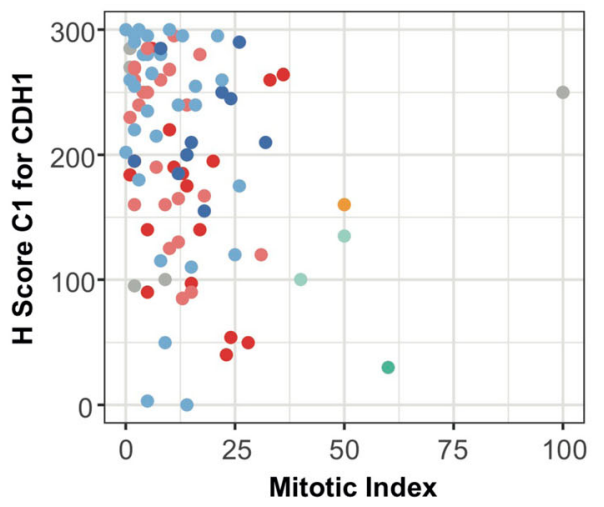

- Control-Luminal A - Case-Luminal A - Control-Her2 - Basal like

- Control - Luminal B • Case - Luminal B • Case - Her2 • Unkwown

Fig. 1 (See legend on next page.) 
(See figure on previous page.)

Fig. 1 Patients with distant relapse exhibit lower CDH1 protein levels and higher Prosigna ${ }^{\mathrm{TM}}$ score than controls. a, b ROR score (a) and risk of distant recurrence at 10 years (b) assessed by Prosigna ${ }^{\mathrm{TM}}$ according to the recurrence status ( $N=99,49$ controls, 50 cases). Horizontal dashed lines split patients according to the risk category, as defined by the Prosigna ${ }^{\mathrm{TM}}$ test as low, intermediate or high risk. $p$ values are from Wilcoxon tests. $\mathbf{c}$ Representative views of $\mathrm{CDH} 1$ (E-cadherin) immunostaining in controls (left) and cases (right) (scale bar $=50 \mu \mathrm{m}$ ). $\mathbf{d}$ Boxplot showing $\mathrm{CDH} 1 \mathrm{H}$ score according to the recurrence status and the molecular subtype ( $N=92,44$ controls, 48 cases). H score were given as a function of percentage of stained cancer cells multiplied by its respective staining intensity (ranging from 0 to 3 ). $\mathbf{e}, \mathbf{f}$ Correlations between $\mathrm{CDH} 1 \mathrm{H}$ score and mitotic index (count of mitotic figures in 10 consecutive high-magnification fields) (e) $(N=92,44$ controls, 48 cases) or between $\mathrm{CDH} 1 \mathrm{H}$ score and ROR score $(\mathbf{f})(N=87,42$ controls, 45 cases). $p$ values are from Spearman's correlation tests. Lobular carcinomas $(N=12,8$ controls, 4 cases) were excluded from all $\mathrm{CDH} 1$ analyses due to their constitutive loss of $\mathrm{CDH} 1$ expression. The color code for boxplots and correlation plots is indicated below the figure. It depicts the BC subtype assessed by Prosigna ${ }^{\mathrm{TM}}$ test. Luminal A BC are in light blue (controls, $\left.N=37\right)$ and light red (cases, $N=27)$. Luminal $B B C$ are in dark blue (controls, $N=11)$ and dark red (cases, $N=19)$. HER2-enriched $B C$ are in light green (controls, $N=2$ ) and dark green (cases, $N=2$ ). The basal-like $B C$ is in yellow. BC without result for Prosigna ${ }^{\text {TM }}$ test are in gray (2 controls and 3 cases)

0.03, $p=0.83$ for controls, Spearman test), suggesting that, for cases, tumor cell differentiation state is linked with $\mathrm{CD} 4+\mathrm{T}$ cell infiltration. In contrast, $\mathrm{CD} 4^{+} \mathrm{T}$ lymphocyte content was not correlated with ROR score (Rho $=-0.16, p=0.09$, Spearman test). Contrary to $\mathrm{CD}^{+}{ }^{+} \mathrm{T}$ lymphocytes, the content in all other immune cells, including cytotoxic $\left(\mathrm{CD}^{+}\right)$, regulatory $\left(\mathrm{FOXP}^{+}\right)$, Th1 (T-Bet $\left.{ }^{+}\right)$, Th17 (IL-17 ${ }^{+}$) T lymphocytes, B lymphocytes $\left(\mathrm{CD} 20^{+}\right)$, mature dendritic cells $\left(\mathrm{DC}-\mathrm{LAMP}^{+}\right)$, macrophages $\left(\mathrm{CD} 163^{+}\right), \mathrm{PD}-\mathrm{L}^{+}$, and $\mathrm{PD}-1^{+}$lymphocytes, was equivalent between cases and controls (Fig. 2c, f-m). Moreover, no PD-L1 staining was detected in epithelial cells, neither in controls nor in cases, thereby precluding any impact of PD-L1 expression in tumor cells in luminal $\mathrm{BC}$ at diagnosis for ulterior relapses. As recently reported $[22,23]$, we observed that the total account of lymphocytes was much lower at the surface of epithelial cancer cells compared to stromal fibroblasts. Indeed, 0 to $12.8 \%$ of the total lymphocyte account was detected at the surface of the epithelium compared to the stroma. Although there was no difference between cases and controls in the content of intra-epithelial immune cells (regardless of population studied) (Additional File 4: Fig. S2), the proportion of $\mathrm{CD}^{+} \mathrm{T}$ lymphocytes at the surface of the stroma was significantly lower in cases than in controls (Additional File 4: Fig. S2) ( $p=0.01$, Wilcoxon test). Based on that observation, we next wondered if the difference in $\mathrm{CD} 4^{+} \mathrm{T}$ lymphocyte infiltration between cases and controls could be due to a distinct vascularization pattern. Using CD31 immunostaining of vascular endothelial cells, we observed higher vascularization in cases than in controls with a median stromal surface of vessels of $1.96 \%$ $(0.22-11.38 \%)$ for cases and $1.27 \%(0.30-14.24 \%)$ for controls $(p=0.009$, Mann-Whitney test, Additional File 5: Fig. S3). Hence, we could conclude that the lower rate of $\mathrm{CD}_{4}^{+}$lymphocyte infiltration in cases was not due to reduced vascularization.

\section{Cases are enriched in the activated CAF-S1 subset}

As there was no clear difference in immune infiltration between cases and controls (except for $\mathrm{CD} 4^{+} \mathrm{T}$ cells), we next aimed to investigate the potential link between fibroblastic stroma and distant relapse in luminal BC. Indeed, while fibroblasts remain one of the most abundant components of the TME, the impact of stromal quantity and heterogeneity on relapse is far from known. We thus performed a global analysis of the stroma, considering both its quantity and its quality, in particular by assessing the repartition of the 4 CAF subsets recently identified in human breast and ovarian cancer [22, 23]. Although the median percentage of intratumoral stroma was $50 \%$, the stromal content was not significantly different between controls and cases $(p=0.73$, MannWhitney test, Additional File 6: Fig. S4). Similarly, using a semi-quantitative score, we found that the proportion of adipose stroma was equivalent between controls and cases ( $p=0.78$, Additional File 6: Fig. S4). We thus evaluated the distinct CAF subsets recently identified [22, 23]. To do so, we analyzed concomitantly the protein level of the same stromal markers as those described in previous studies [22, 23], enabling us to identify the 4 CAF subpopulations. These stromal markers were FAP (fibroblast activation protein $\alpha 1$ ), $\alpha \mathrm{SMA}$, integrin $\beta 1 /$ CD29, S100-A4/FSP1 (fibroblast-specific protein 1), and PDGFR $\beta$ (platelet-derived growth factor receptor- $\beta$ ). CAF subsets have been previously defined as follows: CAF-S1: CD29 ${ }^{\text {Med }}$ FAP $^{\mathrm{Hi}}$ FSP1 $^{\text {Low-Hi }} \alpha S M A^{\mathrm{Hi}}$ PDGF $\mathrm{R} \beta^{\text {Med-Hi }}$; CAF-S2: CD29 ${ }^{\text {Low }}$ FAP $^{\text {Neg }}$ FSP1 $1^{\text {Neg-Low }} \alpha S M A-$ Neg PDGFR $\beta^{\text {Neg }}$; CAF-S3: CD29 ${ }^{\text {Med }}$ FAP $^{\text {Neg }}$ FSP1 $^{\text {Med-Hi }}$ $\alpha S M A^{\text {Neg-Low }}$ PDGFR $\beta^{\text {Med }}$; CAF-S4: CD29 ${ }^{\text {Hi }}$ FAP $^{\text {Neg-Low }}$ FSP1 ${ }^{\text {Low-Med }} \alpha S M A^{\text {Hi }}{ }^{\text {PDGFR }} \beta^{\text {Low-Med }}[22,23]$. To highlight the content in the different CAF subsets, we performed IHC using the 5 aforementioned stromal markers on serial sections from controls and cases (Fig. 3a). All CAF-S1 and CAF-S4 markers accumulated more in cases than in controls: $\alpha$ SMA, $p=0.001$; FAP, $p=0.0001$; CD29, $p=0.01$; PDGFR $\beta, p=0.02$; FSP1, $p=$ 0.05 (Mann-Whitney tests) (Fig. 3b-f). Using a decision tree based on the histological staining of CAF markers developed in [22, 23] and described in (Fig. 3g), we found that early luminal $\mathrm{BC}$ were mostly enriched in CAF-S2 subset (42.3\%), followed by CAF-S4 (29.8\%), 


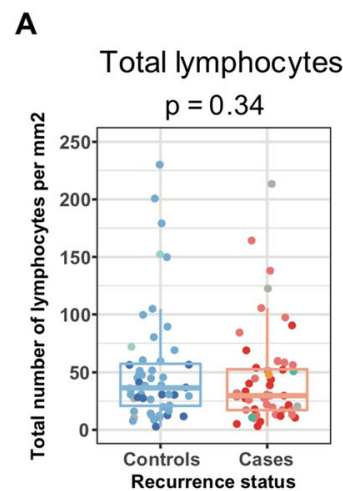

D

Controls

High CD4+ T lymphocytes Low CD4+ T lymphocytes

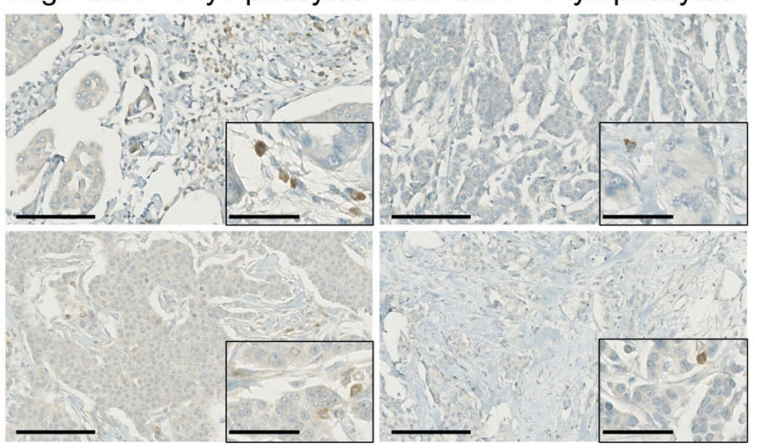

$\mathbf{F}$

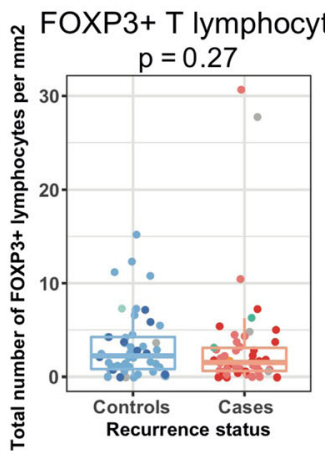

J

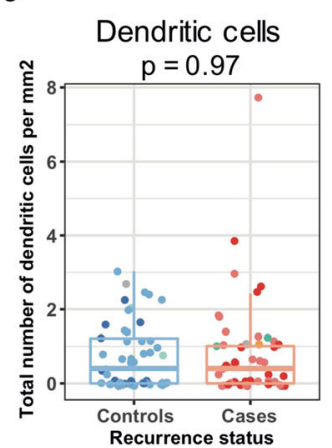

Fig. 2 (See legend on next page.)
B

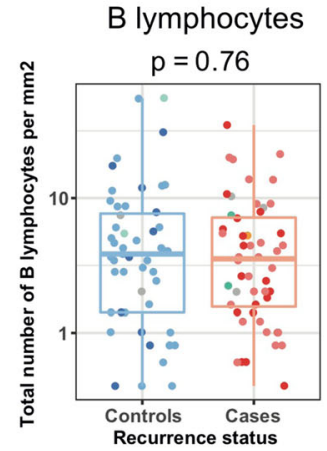

Cases

G

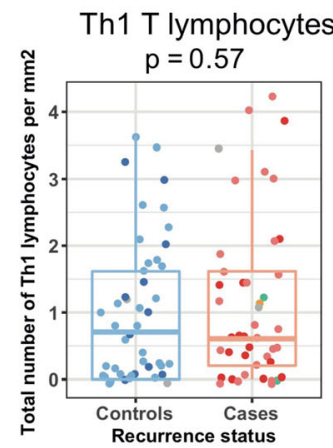

K

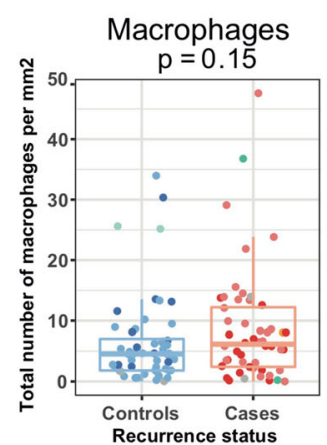

H
C

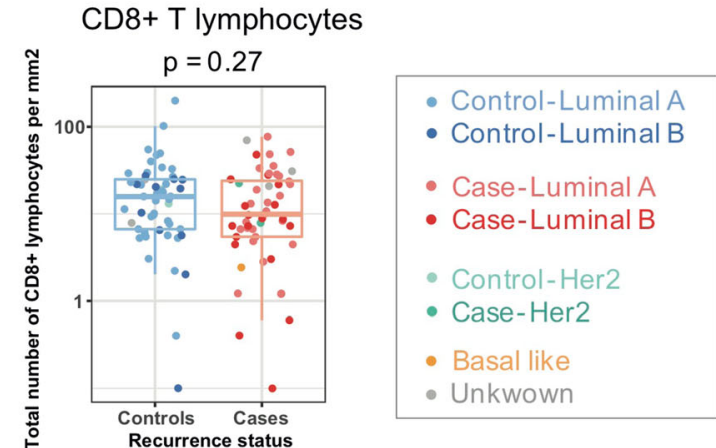

E

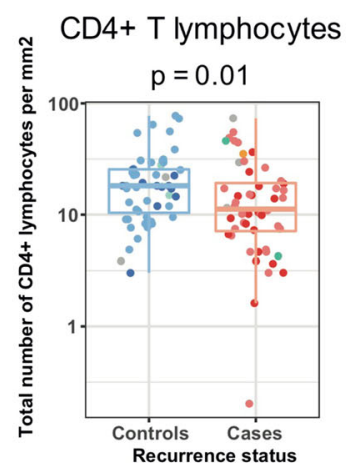

Th17 T lymphocytes

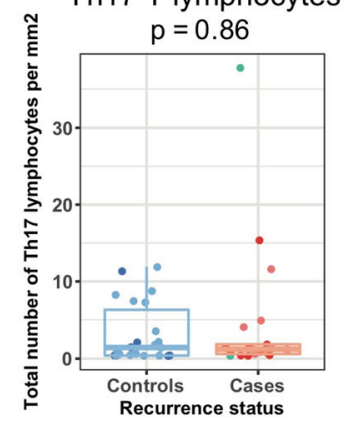

I

$\mathbf{L}$

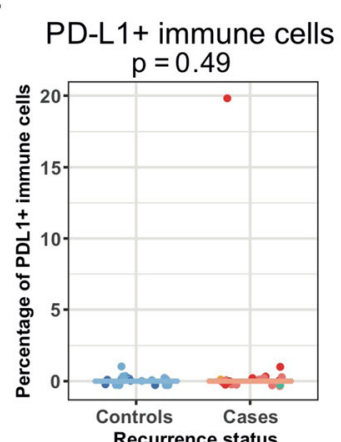

TLS

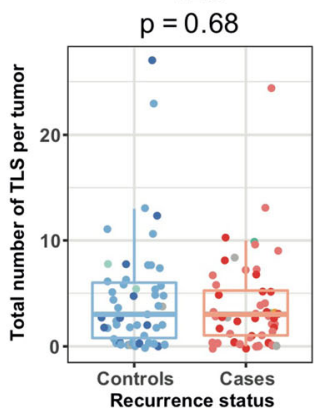

M

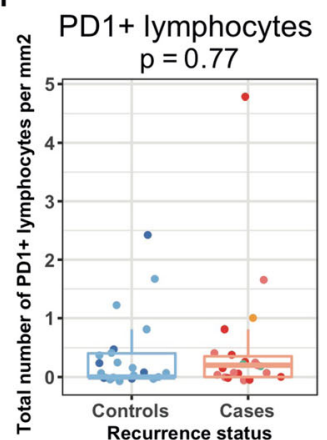


(See figure on previous page.)

Fig. 2 Distant recurrence in luminal breast cancer is not associated with strong modulation of immune infiltration. Boxplots showing total count of stained cells per $\mathrm{mm}^{2}$ for lymphocytes on HES sections (a), B lymphocytes using CD20 marker (b), CD8 ${ }^{+}$T lymphocytes (c), CD4 ${ }^{+} \mathrm{T}$ lymphocytes (e), FOXP3 ${ }^{+}$T lymphocytes (f), Th1 T lymphocytes using Tbet marker (g), Th17 T lymphocytes using IL17 marker (h), TLS count on HES sections (i), dendritic cells using DC Lamp marker (j), macrophages using CD163 marker (k), PD-L $1^{+}$immune cells $(\mathbf{I})$, and PD- $1^{+}$lymphocytes $(\mathbf{m})$ according to the recurrence status and the molecular subtype. $N=104$ patients ( 52 controls and 52 cases) for all immune analyses except for PD-1 and PD-L1 markers ( $N=44,22$ controls, 22 cases). $\mathbf{d}$ Representative views of CD4 + T lymphocytes immunostaining in either controls (left) and cases (right) (scale bar $=100 \mu \mathrm{m}$ for larger views and $50 \mu \mathrm{m}$ for inserts). $p$ values are from Wilcoxon tests. The color code for boxplots is indicated at the top right of the figure. It depicts the $\mathrm{BC}$ subtype assessed by Prosigna ${ }^{\mathrm{TM}}$ test. Luminal $\mathrm{A} B C$ are in light blue (controls, $\left.N=37\right)$ and light red (cases, $N=27$ ). Luminal B BC are in dark blue (controls, $N=11$ ) and dark red (cases, $N=19$ ). HER2-enriched $B C$ are in light green (controls, $N=2$ ) and dark green (cases, $N=2$ ). The basal-like BC is in yellow. BC without result for Prosigna ${ }^{\mathrm{TM}}$ test are represented in gray $(2$ controls and 3 cases)

CAF-S1 (14.4\%), and CAF-S3 (13.5\%) (Fig. 3h). Interestingly, cases were significantly enriched in the CAF-S1 subset that reached $25 \%$ for cases compared to $3.8 \%$ for controls $(p=0.003$, Fisher test comparing CAF-S1 versus other subsets, in cases versus controls) (Fig. 3i, j). Finally, we sought to visualize CAF subsets at a cellular level in both controls and cases. As we could not perform single cell analysis using fresh samples in this rare T1N0 luminal $\mathrm{BC}$ patient cohort, we developed an image analysis tool at cellular level that combined spatial registration and computational analysis on serial consecutive IHC sections (shown in Additional File 6: Fig. S4; see Methods, \#Maps of CAF subsets at cellular level). We applied the CAF decision tree algorithm (described in Fig. 3g) determining CAF subset identity and generated maps of CAF subsets at cellular level (Fig. 3k). In this manner, we could visualize CAF subset spatial distribution in T1N0 luminal BC. Representative pictures of CAF subset maps confirmed the overall enrichment in CAF-S1 in cases compared to controls (Fig. 3k).

Importantly, using multivariate analyses by the Cox proportional hazard model, we observed that distant recurrence in early luminal $\mathrm{BC}$ was associated with the CAF-S1 subset (HR $=5.02 ; \quad$ CI95\% [2.34-10.73]; $p<$ 0.0001 ), independent of any other features analyzed, such as $\mathrm{CDH} 1 \mathrm{H}$ score, ROR risk category, $\mathrm{CD} 4^{+} \mathrm{T}$ lymphocyte infiltration, and macrophage infiltration and vascularization (Table 2). Among the distinct parameters analyzed, cancer cell characteristics, including CDH1 protein levels and ROR risk, either remained significant but with low pertinence (CDH1: HR 1.23; CI95\% [1.007-1.51] $p=0.042$ ) or even lost significance (ROR risk) in multivariate analyses (Table 2), indicating that they are not the most significant indicators of relapse in luminal $\mathrm{BC}$ patients. In contrast, among TME features, the CAF-S1 subset remained the most significant one in multivariate analyses (Table 2), indicating that the CAFS1 subset is a crucial component in relapse of luminal $\mathrm{BC}$. We confirmed the impact of the CAF-S1 content on distant recurrence by using FAP histological scoring, as a specific marker of CAF-S1 quantity per tumor. Interestingly, patients with a high level of FAP showed an earlier distant recurrence rate than patients with a low level of FAP (Fig. 3l). We obtained similar results when we divided $\mathrm{BC}$ patients into three subgroups, with a better prognosis for low-FAP $\mathrm{H}$ score and faster distant recurrence for intermediate- and high-FAP subgroups of patients (Fig. 3l). Taken as a whole, these data demonstrate a "dose-effect" relationship between CAF-S1 content and distant recurrence risk in luminal $\mathrm{BC}$ patients.

\section{Cadherin 11 expression by CAF-S1 enhances cancer cell pro-tumorigenic properties}

As the CAF-S1 subset is one of the main indicators of relapse in luminal $\mathrm{BC}$, we set about identifying the molecular mechanism involved. We first used RNA sequencing analysis from CAF subsets isolated from BC (data deposited at the European Genome-phenome Archive under accession number EGAS00001002508) [22] and found that CDH11 (cadherin 11, also referred to as osteoblast cadherin) was significantly up-regulated in CAF-S1 subset compared to the other CAF subsets (Fig. 4a). CDH11 is involved in bone development and is expressed in cells with a mesenchymal phenotype [4347]. Luminal BC mainly relapse in the bone [48, 49]. This was confirmed in our cohort with 41 cases (78.8\%) showing bone metastases during their evolution. We thus hypothesized that high CDH11 expression in CAFS1 cells could explain, at least in part, the distant relapse in luminal BC. We performed CDH11 IHC on sections of our cohort and observed that CDH11 was mostly detected in CAF and significantly more expressed in the stromal compartment in cases than controls $(p=0.01)$ (Fig. 4b, c). Moreover, CDH11 was also significantly higher in tumors enriched in CAF-S1 compared to others $(p=3.73 \mathrm{e}-06)$ (Additional File 7: Fig. S5). In contrast, $\mathrm{CDH} 11$ expression was weak or even undetectable in tumor cells and without any difference between cases and controls (Additional File 7: Fig. S5). In addition, while $29 \%$ of patients with low CDH11 $\mathrm{H}$ score in stroma showed bone metastases, this proportion reached $49 \%$ in patients with high-CDH11 stromal $\mathrm{H}$ score ( $p=$ 0.06 by Fisher exact test, Additional File 7: Fig. S5). Although this result did not reach significance at $5 \%$, it 


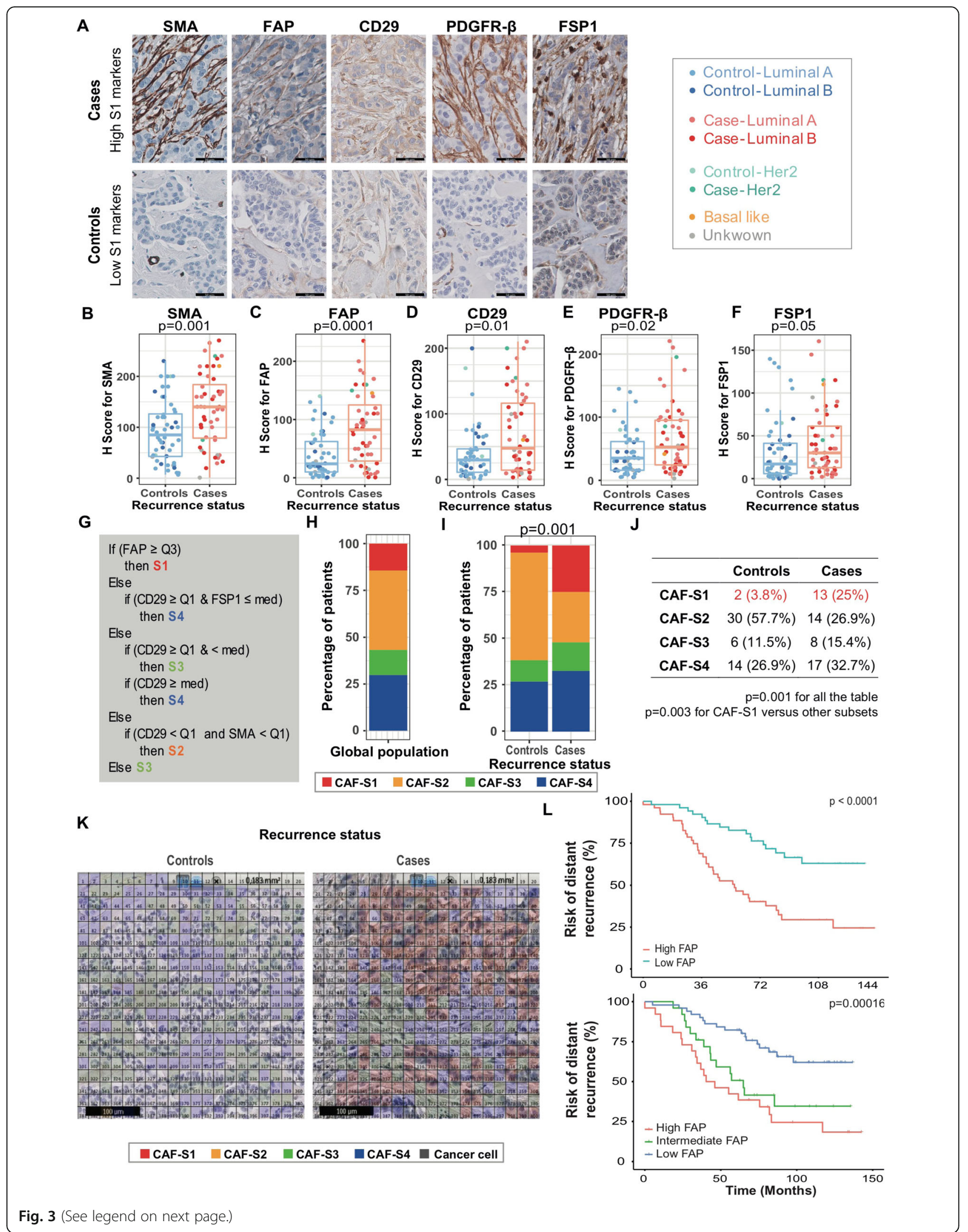


(See figure on previous page.)

Fig. 3 A specific subset of CAF is associated with distant recurrence in luminal breast cancer. a Representative views of SMA, FAP, CD29, PDGFR$\beta$, and FSP1 immunostaining in cases and controls (scale bar $=50 \mu \mathrm{m})$. b-f Boxplots showing histological scores (H scores) for CAF markers (SMA, FAP, CD29, PDGFR- $\beta$, and FSP1) according to recurrence status and molecular subtype ( $N=104,52$ controls, 52 cases). H scores are given as a function of percentage of stained CAF multiplied by its respective staining intensity (ranging from 0 to 3). $p$ values are from Wilcoxon tests. Boxplots color code is indicated below b-f. It indicates the BC subtype d by Prosigna ${ }^{\mathrm{TM}}$ test. Luminal A BC are in light blue (controls, $\left.N=37\right)$ and light red (cases, $N=27$ ). Luminal B BC are in dark blue (controls, $N=11$ ) and dark red (cases, $N=19$ ). HER2-enriched $B C$ are in light green (controls, $N=2$ ) and dark green (cases, $N=2$ ). Basal-like BC are in yellow. BC without result by Prosigna ${ }^{\mathrm{TM}}$ test are in gray $(2$ controls and 3 cases). g Decision tree used to define CAF subset identity according to CAF maker intensities, based on 4 equal quartiles (Q1-Q4) and median (med) distribution of each CAF marker, as shown in [22]. $\mathbf{h}$, i Bar plot showing the distribution of CAF subset enrichment in luminal early BC for all patients (h) and according to the recurrence status (i). For each BC analyzed, enrichment is defined by applying $\mathrm{H}$ scores of all markers on the decision tree described in $\mathbf{g}$. Breast cancer enriched in CAF-S1 (red), CAF-S2 (orange), CAF-S3 (green), or CAF-S4 (blue) are shown as percentage (\%) $(N=104,52$ controls, 52 cases). $p$ value is from Fisher exact test. $\mathbf{j}$ Contingency table for the repartition of CAF subsets enrichment according to the recurrence status ( $N=104,52$ controls, 52 cases). $p$ values are from Fisher exact test. $\mathbf{k}$ Representative views of maps of CAF subsets at cellular scale using the decision tree algorithm (shown in $\mathbf{g}$ ) and CAF marker histological scoring on serial BC sections (corresponding sections and staining shown Additional File 6: Fig. S4). CAF-S1 are in red, CAF-S2 in orange, CAF-S3 in green, and CAF-S4 in blue. Scale bar, $100 \mu \mathrm{m}$. I Left, Kaplan-Meier survival analysis for distant recurrence rate according to low- and high-FAP H scores. Patient subgroups defined by median. $p$ value is from Log-Rank test. Right, same as in left with patients stratified in 3 categories according to FAP H scores: low-FAP if $\mathrm{H}$ score $\leq 47$ ( $N=52$ ), intermediate-FAP if $\mathrm{H}$ score $>47$ and $\leq 95(N=26)$, and high-FAP if $\mathrm{H}$ score $>95(N=26)$. $p$ value is from Log-Rank test

showed enrichment close to significance. This led us to assume that high CDH11 expression in CAF-S1 could be involved, at least in part, in bone relapse in T1N0 luminal BC patients. We thus performed in vitro functional assays to decipher the crosstalk between luminal cancer cells and CAF-S1 fibroblasts and investigate the impact of CDH11 silencing into CAF-S1 cells (see Additional File 8: Fig. S6 for silencing efficiency) on cancer cell features. We first verified that CDH11 silencing had no effect on CAF-S1 proliferation rate and survival (Additional File 8: Fig. S6) and next studied its impact on two BC cell lines, i.e., MCF7 and T47D, well-known

Table 2 Univariate and multivariate analyses for using Cox model for risk of distant relapse according to cancer cell and tumor microenvironment features

\begin{tabular}{|c|c|c|c|c|c|c|}
\hline & \multicolumn{3}{|c|}{ Univariate analyses } & \multicolumn{3}{|c|}{ Multivariate analyses } \\
\hline & $\mathrm{HR}$ & C195\% ] & $p$ value & $\mathrm{HR}$ & C195\% [ & $p$ value \\
\hline \multicolumn{7}{|l|}{ CDH1 } \\
\hline Range 250-300 & Ref & - & - & Ref & - & - \\
\hline Per decrease of 50 pts & 1.21 & [1.03-1.44] & 0.02 & 1.23 & [1.007-1.51] & 0.04 \\
\hline \multicolumn{7}{|l|}{ ROR risk category } \\
\hline Low risk & Ref & - & - & Ref & - & - \\
\hline Intermediary risk & 1.98 & {$[0.98-4.00]$} & 0.05 & 1.68 & {$[0.75-3.76]$} & 0.20 \\
\hline High risk & 2.45 & [1.20-4.98] & 0.01 & 1.62 & {$[0.67-3.91]$} & 0.28 \\
\hline \multicolumn{7}{|l|}{ CAF subset } \\
\hline S1 & 3.98 & {$[2.09-7.59]$} & $<0.0001$ & 5.02 & [2.34-10.73] & $<0.0001$ \\
\hline $\mathrm{S} 2, \mathrm{~S} 3$, or S4 & Ref & - & - & Ref & - & - \\
\hline \multicolumn{7}{|l|}{ CD4 ${ }^{+}$lymphocytes } \\
\hline Low & 1.88 & [1.07-3.30] & 0.02 & 2.973 & {$[1.50-5.88]$} & 0.001 \\
\hline High & Ref & - & - & Ref & - & - \\
\hline \multicolumn{7}{|l|}{ Macrophages } \\
\hline Low & Ref & - & - & Ref & - & - \\
\hline High & 1.84 & [1.04-3.22] & 0.03 & 1.60 & [0.83-3.09] & 0.15 \\
\hline \multicolumn{7}{|l|}{ CD31 ${ }^{+}$vessels } \\
\hline Low & Ref & - & - & Ref & - & - \\
\hline High & 1.73 & [0.99-3.07] & 0.05 & 2.56 & [1.32-4.97] & 0.005 \\
\hline
\end{tabular}

Level of markers was determined using the median $\mathrm{H}$ score

Lobular carcinomas were excluded from analysis using E-cadherin $(N=12)$

$C A F$ cancer-associated fibroblasts, $\mathrm{Cl}$ confidence interval, $H R$ hazard ratio, Pts points 


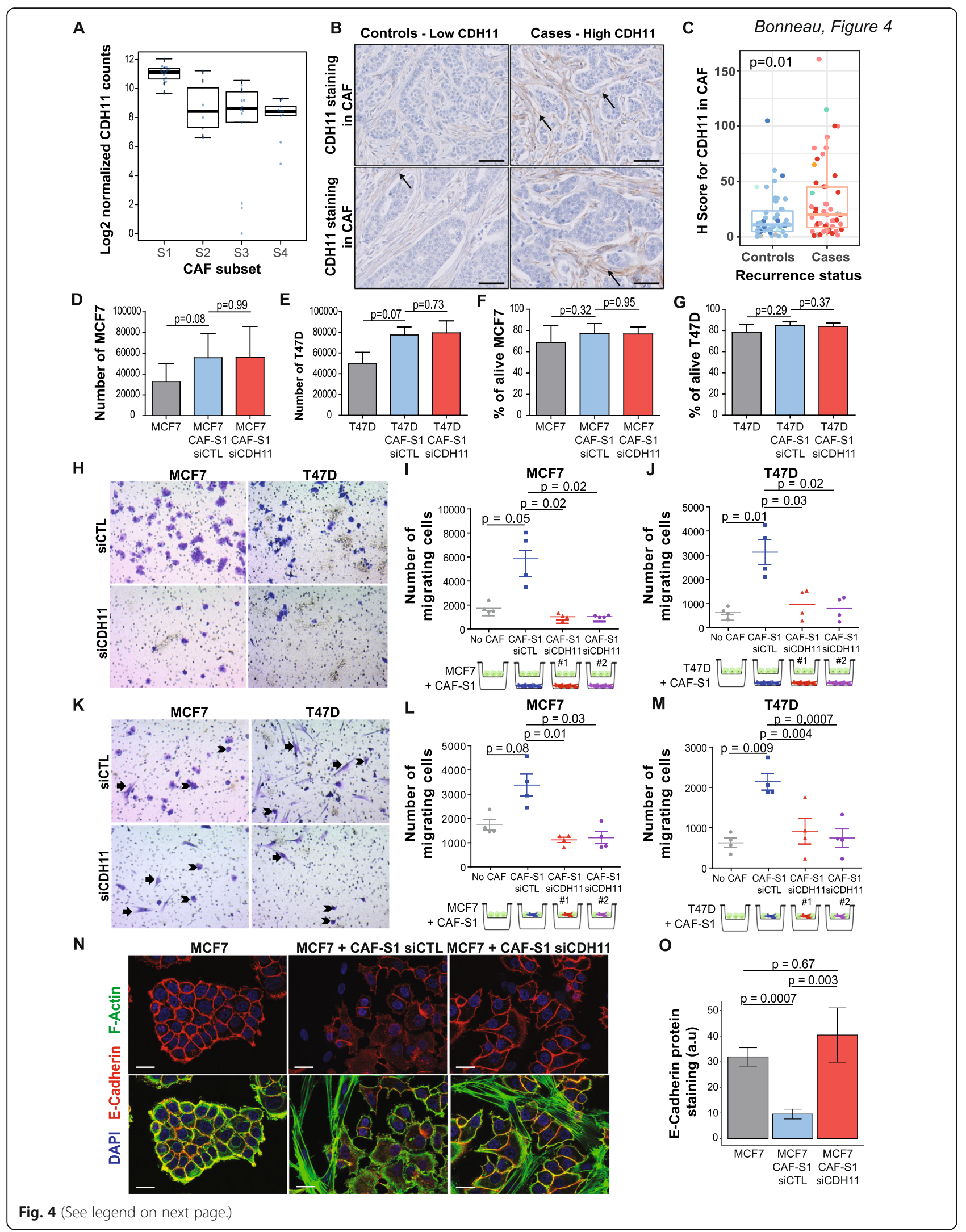




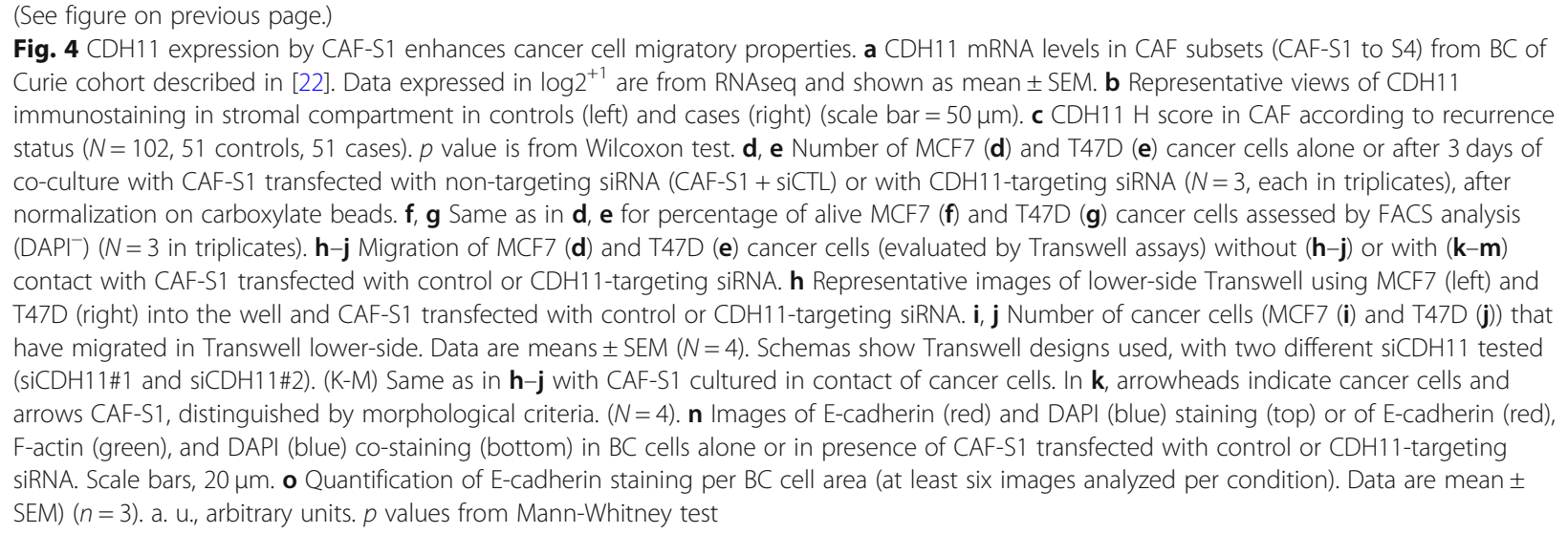

for their luminal properties. Moreover, we verified that CAF-S1 primary fibroblasts isolated from $\mathrm{BC}$ patients exhibited the same molecular identity as CAF-S1 fibroblasts without culture, as demonstrated in [38]. After 3 days of co-culture, CAF-S1 primary fibroblasts tended to increase MCF7 and T47D proliferation, although without reaching significance; and $\mathrm{CDH} 11$ silencing in CAF-S1 had no impact on the total number of cancer cells (Fig. 4d, e). Similarly, the survival rate of these two cancer cell lines was not affected by CDH11 silencing in CAF-S1 cells (Fig. 4f, g). Importantly, using Transwell assays we observed that, in close contact or even at distance, CAF-S1 fibroblasts increased the migration of MCF7 and T47D luminal BC cell lines (Fig. 4h-m). Interestingly, $\mathrm{CDH} 11$ silencing in CAF-S1 significantly inhibited the migration of these luminal $\mathrm{BC}$ cells (Fig. 4h-m), highlighting the impact of CDH11 in CAFS1 cells on the migratory capacity of luminal BC cells. We could not exclude that, upon co-culture with CAFS1 cells (as in Fig. 4h-j), BC cells initiated a first step of epithelial-to-mesenchymal transition conferring a "mesenchymal-shape" to BC cells. However, data shown in (Fig. 4k-m) were based on the distant effect of CAF-S1 fibroblasts. In these conditions, only cancer cells were on the top part of the Transwell and strictly analyzed in terms of migration. In these experimental settings, CAFS1 fibroblasts enhanced $\mathrm{BC}$ cell migration without contact, an effect which was lost when $\mathrm{CH} 11$ was inhibited (Fig. 4l, m). Finally, in agreement with reduced tumor cell migration upon CDH11 silencing in CAF-S1 fibroblasts, we found that these conditions had an impact on CDH1/E-cadherin protein levels in both MCF7 and T47D tumor cells. Indeed, upon co-culture of CAF-S1 and tumor cells, CAF-S1 fibroblasts significantly decreased CDH1/E-cadherin protein levels in tumor cells, as we recently demonstrated in [38]. Interestingly, we observed that CDH11 silencing in CAF-S1 prevented this effect and kept the $\mathrm{CDH} 1 / \mathrm{E}$-cadherin protein level elevated at the surface of MCF7 and T47D tumor cells
(Fig. 4n, o and Additional File 8: Fig. S6). Maintenance of $\mathrm{CDH} 1 / \mathrm{E}$-cadherin protein levels in tumor cells upon co-culture with CAF-S1 could explain the reduction of tumor cell migration we observed upon CDH11 silencing in CAF-S1. These new data highlight the mechanism by which CDH11 act on cancer cell migration and give new insights into CAF-S1-mediated CDH11 function on cancer cell metastatic spread in luminal breast cancer. Thus, high expression of CDH11 in CAF-S1 fibroblasts in luminal $\mathrm{BC}$ increases the pro-migratory capacity of luminal $\mathrm{BC}$ cells, thereby giving insights of the role of CAF-S1 in distant relapse in luminal BC.

\section{Discussion}

Although T1N0 luminal BC patients often exhibit a good prognosis, 5 to $10 \%$ of patients will relapse and ultimately die. The generally high rate of their survival explains in part the paucity of studies on these patients until now $[9,10]$. Here, we address the question of distant metastases in these early luminal $\mathrm{BC}$ patients by combining analyses on both epithelial and stromal compartments. We found that relapse in early luminal BC is associated with both tumor cell-autonomous and nonautonomous effects. In particular, we demonstrate that one main mechanism of relapse in these patients is mediated by a specific CAF subset, referred to as CAF-S1. This CAF-S1-dependent effect on relapse is independent of the tumor cell-autonomous effects, including differentiation state and proliferation. Moreover, the CAF-S1mediated effect on relapse provides an additive value to immune infiltrate and blood vessel vascularization. Finally, we established that the CDH11/osteoblast cadherin, which is highly expressed by CAF-S1 and accumulates in cases compared to controls, increases migration properties of luminal $\mathrm{BC}$ cells.

The prognosis of luminal $\mathrm{BC}, \mathrm{T} 1 \mathrm{~b}-\mathrm{cN}$, is very favorable, as confirmed in our cohort. Among the 3739 patients suitable for inclusion in the Curie cohort, only 71 patients had distant metastatic recurrence $(97.8 \%$ of 
distant recurrence-free survival at 5 years). The "casecontrol" design of our cohort was specially adapted to this situation, as the occurrence of the event (i.e., metastatic recurrence) is rare. To our knowledge, this is the first "case-control" study to address the issue of metastatic recurrence in patients with small $\mathrm{BC}$ and generally of good prognosis. Although the number of patients with metastatic relapse is low, it is important to better understand the mechanisms and risk factors involved in recurrence. On the one hand, identification of high-risk patients might justify an increase in adjuvant treatments in order to prevent recurrence; on the other hand, this could lead to a decrease in adjuvant therapies in low risk patients to avoid treatment side effects. Importantly, none of the clinicopathological criteria commonly used in clinics (i.e., histological subtype, percentage of ER or PR, grade, size, neoplastic emboli) were significantly different between cases and controls. This may explain why patient prognosis is currently difficult to assess in clinics and reinforces the clinical value of our study.

We firstly established that reduced CDH1/E-cadherin protein level was associated with metastatic recurrence. Previous studies have already reported an association between low $\mathrm{CDH} 1$ expression and increased risk of recurrence [40-42, 50-56]. However, other clinical studies did not confirm this association and contradictory reports were published on the utility of $\mathrm{CDH} 1$ assessment as an independent prognostic marker in invasive $\mathrm{BC}$ [57-60]. Moreover, these studies were neither dedicated to small luminal BC nor performed on sub-stratified patients, thereby highlighting the interest of our study. The association between reduced $\mathrm{CDH} 1$ protein levels and recurrence risk is possibly due to the epithelial-tomesenchymal transition [61], although some studies have shown that CDH1-mediated cell-cell adhesion can promote chemoresistance and cell survival in the blood circulation [62-65]. Still, a CDH1-mediated effect remains at the limit of significance in multivariate analysis in our study. Similarly, although the ROR score estimated by Prosigna ${ }^{\text {Tw }}$ test was significantly different between controls and cases, this difference was small in absolute value with poor discrimination. As the PAM50 signature used in the Prosigna ${ }^{\text {Ta }}$ test relies on proliferation genes, the difference between the two subgroups could be minimized by the initial adjustment on proliferation rate we used to match controls to cases [12]. This suggests that other prognostic factors identified here, such as TME components, might be more relevant than tumor cell features in luminal BC patient relapse.

Luminal $\mathrm{BC}$ are known to be poorly immunogenic compared to HER2 or triple-negative BC. By performing a global analysis of a large panel of cells from innate and acquired immunity and biomarkers for immunotherapies, we confirmed that $\mathrm{T}$ lymphocyte infiltration is rather weak (about 30 lymphocytes $/ \mathrm{mm}^{2}$ on average) in early luminal BC. Consistent with the existing literature on the lack of prognostic value of $\mathrm{T}$ lymphocytes in luminal BC [66-69], we also found that the overall density in $\mathrm{T}$ cells or in $\mathrm{CD} 8^{+} \mathrm{T}$ lymphocytes was not associated with metastatic recurrence. However, we observed a lower rate of $\mathrm{CD} 4^{+} \mathrm{T}$ lymphocytes in patients with metastatic recurrence than in controls, an effect that needs to be confirmed in other cohorts as little evidence exists regarding the prognostic value of $\mathrm{CD} 4^{+} \mathrm{T}$ lymphocytes in luminal BC. Besides, PD-1 and PD-L1 expression was weak with very little inter-tumor variation. Although we could not exclude that the low PD-L1 staining in TILs was not linked to technical difficulties in maintaining good immunoreactivity of embedded tissues once sectioned [70], our findings confirmed previous data on luminal $\mathrm{BC}$ patients $[71,72]$ that showed low PD-1 and PD-L1 expression in luminal BC and were not in favor of anti-PD-1 or PD-L1 use in luminal BC type.

In contrast to the immunological content, enrichment in CAF-S1 fibroblasts is a new risk factor for recurrence in early luminal $\mathrm{BC}$, independent of epithelial, immune, and vascular features. Several fibroblast markers ( $\alpha$ SMA, FAP, CD29, PDGFR $\beta$ ) are associated with metastatic recurrence. Previous studies have shown that increased expression of $\alpha \mathrm{SMA}$ in $\mathrm{BC}$ stroma is associated with highgrade, nodal invasion, increased neovascularization, and poor prognosis [17, 73-75]. To our knowledge, the characterization of the CAF-S1 subset and its implication in distant relapse have never been established. Transcriptomic signatures of genes involved in ECM remodeling, immunity, and angiogenesis have been developed recently [22, 25, 76-82]. Most of them have been developed from cohorts including all BC types and stages. Tumor stromal prognostic value was independent of ER or HER2 expression, grade, age, chemo- or endocrine-therapy [80], highlighting the importance of stromal biology in tumor progression and patient clinical outcome. In that context, our study confirms the existence of 4 CAF subpopulations in luminal $\mathrm{BC}$, as observed previously in luminal A BC [22]. Unfortunately, due to the rare occurrence of distant recurrence in the T1N0 luminal BC subpopulation, we could not confirm this finding using prospective single cell analysis from fresh tumor samples. Still, we found a particularly strong prognostic value of CAF-S1 independent of epithelial, immune, and vascular features. Moreover, we observed that CAF-S1-mediated effects were not linked to their previously described immunosuppressive function [2124]. Here, we noted higher vascularization in cases than in controls. This increased vascularization is independent of CAF enrichment and $\mathrm{CD} 4^{+} \mathrm{T}$ cell infiltration, as shown by multivariate analysis. These observations are 
in accordance with previous data showing that high micro-vessel density was significantly associated with poor prognosis in high-grade luminal A BC patients [83]. In the NSABP B-40 clinical trial evaluating bevacizumab (antiVEGF targeted therapy) efficiency in advanced BC, the addition of neoadjuvant plus adjuvant bevacizumab lead to a significant increase in overall survival, especially in hormone-receptor-positive BC patients [84]. Treatment exhibited a strong effect on distant metastases and its efficiency was even stronger beyond 2 years of follow-up, suggesting a predominant effect on undetectable micrometastases present at the time of diagnosis. These data might encourage further investigation into vascular supply in luminal BC. Taken as a whole, our study is original as it deciphers the role of the TME in the rare medical situation where a patient with a very good prognosis shows, in contrast, late relapse with metastases. Hence, the novelty of our manuscript is based on the discovery of an excess risk of distant recurrence linked to the TME and not only linked to tumor cells, as it is usually described. The notion described here thus highlights that early luminal $\mathrm{BC}$ may relapse not only because of aggressive tumor cells but also (and more significantly) because of a permissive microenvironment.

Our study found an increased expression of CDH11 in the stroma of $\mathrm{BC}$ cases compared to controls, consistent with CAF-S1 accumulation. In contrast, epithelial expression of CDH11 was not different between cases and controls, while CDH11 was shown to be overexpressed in basal-like breast cancer [45-47, 85]. Using functional assays, we found that inhibition of CDH11 expression in CAF-S1 fibroblasts significantly reduced CDH1/E-cadherin expression in tumor cells and CAF-S1-mediated pro-migratory effects on $\mathrm{BC}$ cell lines, thereby highlighting that $\mathrm{CDH} 11$ is a new key player in relapse in early luminal BC. This effect was detected both in contact, as well as at a distance, suggesting the role of secreted factors by CAF$\mathrm{S} 1$ in a CDH11-dependent manner. Some studies have previously highlighted the existence of a cleaved secreted CDH11 isoform [86, 87]. Although we could not detect this isoform in CAF-S1 cellular extracts and corresponding supernatants, we could hypothesize that $\mathrm{CDH} 11$ secreted isoform might be involved in the distant effect of $\mathrm{CDH} 11$ on cancer cell migration. CDH11 is already a therapeutic target in rheumatoid arthritis, an inflammatory disease with properties shared with cancer [88, 89]. Systemic administration of anti-CDH11 antibodies restricts the proliferation and migration of synoviocytes to inflammatory joints and decreases the symptoms of rheumatoid arthritis [88]. In $\mathrm{BC}$, the administration of anti-CDH11 antibodies significantly inhibited the growth of the triple-negative MDA-MB-231 xenografts [47]. CDH11 inhibitors could thus be interesting target drugs for $\mathrm{BC}$ overexpressing $\mathrm{CDH} 11$ with high risk of relapse.
Our work also demonstrates the urgency of having in clinical practice tools that would integrate all clinical and biological data, including tumor, immune, and fibroblastic features, to help with prognostic stratification and thus therapeutic decision-making.

\section{Conclusions}

Our study provides one of the first deep analyses of features of tumor cells and their micro-environment associated with distant recurrence in small node-negative (T1N0) luminal BC, patients who have typically been less studied than other $\mathrm{BC}$ subtypes, despite their high frequency at time of diagnosis. In particular, we show that a specific subset of CAF (referred to as CAF-S1) significantly accumulates in tumors with distant relapse. Moreover, we identify CDH11 as a key player in CAFS1-mediated pro-metastatic activity. These findings could help clinicians identify luminal BC with high risk of relapse. Moreover, targeted therapies against CAF-S1 using anti-FAP antibody or compounds targeting CDH11 might be of interest in the prevention of relapse in early luminal BC patients with stroma activation.

\section{Supplementary information}

Supplementary information accompanies this paper at https://doi.org/10. 1186/s13058-020-01311-9.

Additional file 1: Fig. S1. Related to Methods (\# Patient cohort) and Table 1. Flow chart for selecting the population of BC patients studied and corresponding survival curves. Flow chart for selecting cases and controls in our cohort (A) and survival analysis of the population of interest $(N=3739)$ for the recurrence rate $(B)$ and the distant recurrence rate $(C)$. Briefly, the population of interest was female patients with unifocal invasive breast cancer, T1b or T1C N0 M0 (BC smaller or equal to $2 \mathrm{~cm}$, without invaded lymph node and distant metastasis at diagnosis), expressing ER without overexpression of HER2, treated at Institut Curie by at least primary surgery between 2003 and $2010(N=3739)$. Survival curves were constructed according to Kaplan-Meyer method.

Additional file 2: Table S1. Related to Methods (\# Immunohistochemistry). List of primary antibodies and immunohistochemistry conditions used in the study.

Additional file 3: Table S2. Related to Fig. 1. Multivariate analysis using Cox model for risk of distant relapse according to $\mathrm{CDH} 1$ (E-Cadherin) expression and proliferation rates.

Additional file 4: Fig. S2. Related to Fig. 2. Immune profiling in control luminal $B C$ and cases with recurrence. Boxplots showing the count of stained cells per $\mathrm{mm}^{2}$ at the surface of epithelial (left) and stromal (right) compartments for total lymphocytes on HES sections (A), B lymphocytes using CD20 marker (B), CD8 ${ }^{+}$T lymphocytes (C), CD4 ${ }^{+} \mathrm{T}$ lymphocytes (D), FOXP3 $^{+}$T lymphocytes (E), Th1 T lymphocytes using Tbet marker (F), Th17 T lymphocytes using IL17 marker (G), dendritic cells using DC Lamp marker $(\mathrm{H})$, macrophages using CD163 marker $(\mathrm{I})$ and $\mathrm{PD}-1^{+}$lymphocytes $(\mathrm{J})$. Data are shown according to the recurrence status. $N=104$ patients (52 controls in blue and 52 cases in red) for all analyses, except for PD-1 and PD-L1 markers ( $N=44,22$ controls, 22 cases). P-values are from Wilcoxon test.

Additional file 5: Fig. S3. Related to Fig. 2. Increased vascularization is associated with distant relapse. (A) Representative views of CD31 immunostaining in either controls (left) and cases (right) (Scale bar = 100um). (B) Boxplot showing the percentage of CD31+ areas normalized on stroma proportion according to recurrence status and BC molecular subtype ( $N=104,52$ controls and 52 cases). P-value is from Wilcoxon test. 
Additional file 6: Fig. S4. Related to Fig. 3. Stroma proportion and content in adipocytes. (A) Percentage of stroma according to recurrence status. The color code in boxplots depicts the BC subtype assessed by Prosigna $^{\mathrm{TM}}$ test. Luminal $\mathrm{A} B C$ are in light blue (controls, $N=37$ ) and light red (cases, $N=27$ ). Luminal $B$ BC are in dark blue (controls, $N=11$ ) and dark red (cases, $N=19$ ). HER2-enriched $B C$ are in light green (controls, $N=2$ ) and dark green (cases, $N=2$ ). The basal like $B C$ is represented in yellow. BC without result for Prosigna ${ }^{\mathrm{TM}}$ test are in gray (2 controls and 3 cases). P-value is from Wilcoxon test. (B) Proportion of intratumoral adipocytes according to recurrence status. Controls are in blue and cases are in red. P-value is from Chi2 test. The adiposity of the stroma was evaluated using a semi-quantitative scoring: 0 when the adipose content of the stroma was less than $1 \%$ of the surface, 1 between 1 and $10 \%, 2$ between 11 and $30 \%$ and 3 if superior to $30 \% . N=104,52$ controls and 52 cases. (C) Representative views of CAF marker immunostaining on serial sections from control and case BC patients used for building maps of CAF subsets at cellular scale (shown Fig. 3K) using the decision tree algorithm (shown Fig. 3G).

Additional file 7: Fig. S5. Related to Fig. 4. $\mathrm{CDH} 11$ expression in tumors. (A) Boxplot showing $\mathrm{CDH} 11 \mathrm{H}$ scores in CAF according to the CAF status (CAF-S1 compared to others) and BC molecular subtype ( $N=102,51$ controls and 51 cases). $\mathrm{H}$ scores are given as a function of percentage of stained CAF multiplied by staining intensity (ranging from 0 to 3 ). P-value is from Wilcoxon test. The color code depicts the BC subtype assessed by Prosigna ${ }^{\text {TM }}$ test. Luminal $A B C$ are in light blue (controls, $N=37$ ) and light red (cases, $N=27$ ). Luminal $B$ BC are in dark blue (controls, $N=10$ ) and dark red (cases, $N=18$ ). HER2-enriched BC are in light green (controls, $\mathrm{N}=2$ ) and dark green (cases, $N=2$ ). Basal-like $B C$ is in yellow (case, $N=1$ ). $B C$ without result for Prosigna ${ }^{T M}$ test are in gray (2 controls and 3 cases). (B) Same as in (A) for CDH1 $1 \mathrm{H}$ scores in epithelial cancer cells. (C) Representative views of CDH11 immunostaining in epithelial cancer cells (arrows) in controls (left) and cases (right) (Scale bar = $50 \mu \mathrm{m}$ ). (D) Contingency table for the repartition of patients with bone metastases according to the stromal $\mathrm{CDH} 11 \mathrm{H}$ score. $P$-value is from Fisher exact test.

Additional file 8: Fig. S6. Related to Fig. 4. Multiple controls upon silencing of CDH11 by siRNA in CAF-S1. (A) Representative western blot (WB) showing $\mathrm{CDH} 11$ protein levels (expected molecular weight at $110 \mathrm{kDa}$ ) after 3 , 5 and 7 days of transfection of CAF-S1 fibroblasts with $\mathrm{CDH} 11$-targeted siRNA (siCDH11, pool), and compared to untargeted control siRNA (siCTL). Actin (43 $\mathrm{kDa}$ ) is used as internal control for protein loading. (B) Barplot showing quantification of $\mathrm{CDH} 11$ protein levels (assessed by WB, as shown in A) following transfection by siCDH11 and normalized to siCTL (C) Relative CDH11 mRNA levels assessed by RT-qPCR following 48 and $72 \mathrm{~h}$ (H48 and H72) of transfection of CAF-S1 primary fibroblasts with siCDH11 (pool). Data have been normalized on siCTL and cyclophilin mRNA levels for total RNA quantity. (D) Representative WB showing CDH11 protein levels after 3 days of transfection by two siCDH11 (siCDH11\#A and siCDH11\#B) in two CAF-S1 primary cell lines (CAF-S1 A and CAF-S1 B) and compared to untargeted control siRNA (siCTL). Actin $(43 \mathrm{kDa}$ ) is used as internal control for protein loading. (E) Barplots showing quantification of $\mathrm{CDH} 11$ protein levels (assessed by WB, as shown in D) and normalized to siCTL. (F) Representative WB showing $\mathrm{CDH} 11$ protein levels after 3 and 7 days (D3 and D7) of CAF-S1 primary fibroblasts with siCDH11 or siCTL in co-culture conditions in presence of MCF7 cancer cells. (Al $790 \mathrm{Ko})$. (G-H) Number of CAF-S1 cells transfected with non-targeting siRNA (siCTL) or with $\mathrm{CDH}$ 11-targeting siRNA (siCDH11), after normalization on carboxylate beads (G) and percentages (\%) of alive CAF-S1 cells reported to total number of CAF-S1 (H) upon CDH11 silencing compared to control at 0, 72, 120 and $144 \mathrm{~h}$ after transfection. Data are mean $\pm \mathrm{SEM})(n=4)$. $P$ values are from Mann-Whitney test. (I) Representative image of lower-side Transwell using CAF-S1 into the well. We can observe that migrated CAF-S1 fibroblasts (arrows) are morphologically different from migrated T47D or MCF7 BC cells (shown in Fig. 4H). (J) Images of E-cadherin staining in T47D BC cells in presence of CAF-S1 transfected with control (left) or CDH11-targeting siRNA (right). Scale bars, $20 \mu \mathrm{m}$. (K) Quantification of E-cadherin staining per BC cell area (at least three images analyzed per condition). Data are mean $\pm \operatorname{SEM}(n=3)$. a. u., arbitrary units. P-value from Student t-test.

\section{Abbreviations}

ATCC: American Type Culture Collection; BC: Breast cancer; BCA : Bicinchoninic acid assay; BMI : Body mass index; BSA : Bovine serum albumin; CAF: Cancer-associated fibroblasts; CAF-S1-4: CAF subset 1-4; CD29: Integrin B1; CDH1: E-cadherin; CDH11: Osteoblast cadherin-11; Cl95\% : 95\% confidence interval; CNIL : Commission Nationale de l'informatique et des Libertés; CTL : Control; DC: Dendritic cells; DAPI : 4',6-Diamidino-2phenylindole; DC LAMP : Dendritic cell lysosomal associated membrane glycoprotein; DMEM : Dulbecco's modified Eagle medium; DNA

: Deoxyribonucleic acid; ECM: Extracellular matrix; EDTA : Ethylene-diaminetetra-acetic acid; EGTA : Egtazic acid; EPCAM : Epithelial cell adhesion molecule; ER: Estrogen receptor; FACS: Fluorescence activated cell sorting; FAP: Fibroblast activation protein; FBS: Fetal bovine serum; FOXP3 : Forkhead box P3; FSC-A: Forward scatter-A; FSP1/S100-A4 : Fibroblast-specific protein 1 H\&E : Hematoxylin and eosin; HER2 : Human epidermal growth factor receptor-2; HR : Hazard ratio; H score : Histological score; IC : Institut Curie; IHC : Immunohistochemistry; IL17: Interleukin 17; MOPS SDS : Sodium dodecyl sulfate 3-(N-morpholino) propanesulfonic acid; PBS : Phosphatebuffered saline; PCR : Polymerase chain reaction; PD-1 : Programmed cell death 1; PD-L1 : Programmed death-ligand 1; PDGFRß: Platelet-derived growth factor receptor- $\beta$; PR: Progesterone receptor; qRT-PCR : Quantitative reverse transcription polymerase chain reaction; RNA : Ribonucleic acid; ROR: Risk of recurrence (score defined by the Prosigna ${ }^{\text {TM }}$ test); RPM : Revolutions per minute; RPMI : Roswell park memorial institute medium; RPPA : Reverse phase protein arrays; RT-PCR : Reverse transcription polymerase chain reaction; SEM : Standard errors of mean; siRNA : Small interfering RNA; aSMA : Smooth-muscle a-actin; SSC-A : Sidewards scatter-A; STR : Short tandem repeat; T-Bet : T-box transcription factor; Th1 : Type 1 T helper lymphocyte; Th17: Type 17T helper lymphocyte; TILs: Tumorinfiltrating lymphocytes; TLS : Tertiary lymphoid structures; TME : Tumor micro-environment; T1NO : Tumors with a size $\leq 2 \mathrm{~cm}$ and without regional lymph node metastases, as defined by the 8th edition of American Joint Committee on Cancer classification

\section{Acknowledgements}

We are grateful to Melissa Cardon for her help and advice for multiplex analyses, as well as Renaud Leclere, Laetitia Lesage, and André Nicolas for their help at the experimental pathology platform. We thank Diane De Croze for her advice regarding histopathology.

\section{Authors' contributions}

F.M-G. conceived the project and designed the experiments. C.B., D.H., and R.R. built the control-case cohort of patients. C.B., A.E., B.B., and F. P. performed the experiments and acquired the data. D.D.C, JM.G., and A.V-S. provided expertise in pathology analysis. C.B. performed bioinformatic and statistical analyses, with the help of Y.K.. JM.G., A.R., C.B., and A.V-S. provided human samples from the Curie cohort. F.M-G. supervised the entire project and wrote the paper with C.B., with suggestions from all authors. The author(s) read and approved the final manuscript.

\section{Funding}

C.B. was supported by the Institut National de la Santé et de la Recherche Médicale (Inserm, Plan Cancer - Formation à la recherche translationnelle), A.E. by the association d'aide en Cancérologie de Saint-Cloud (ARCS), and Y.K. by the Institut National du Cancer, INCa (INCa-DGOS-9963; INCa-11692), SIRIC (INCa-DGOS-4654), and the Fondation pour la Recherche Medicale (FRM). The experimental work was supported by grants from the Ligue Nationale Contre le Cancer (Labelisation), Inserm (PC201317), Institut Curie (Incentive and Cooperative Program Tumor Micro-environment PIC TME/TMEGA, PIC3i CAFi), ICGex (ANR-10-EQPX-03), SIRIC (INCa-DGOS-4654), and INCa (STROMAE INCa-DGOS-9963, CaLYS INCa-11692, INCa-DGOS-Inserm12554). F.M-G acknowledges both the Association "Le cancer du sein, Parlons-en" and the Simone and Cino del Duca Foundation for attribution of their "Grand Prix". F.M-G is very grateful to all her funders for providing support throughout the years.

\section{Availability of data and materials}

All remaining data and materials are available from the authors upon reasonable request.

\section{Ethics approval and consent to participate}

All patients included in our study and treated at IC were informed by their referring oncologist that their biological samples could be used for research 
purposes. All patients signed informed consent of non-opposition for the collection of excessive tumor samples and molecular analysis.

\section{Consent for publication}

All authors have given consent for publication.

\section{Competing interests}

F.M-G. received research support from Innate-Pharma, Roche and BristolMyers-Squibb (BMS). R. R received financial support for research (travel reimbursement) and speaker honoraria from Nanostring Technologies. Other authors declare no potential conflict of interest.

\section{Author details}

${ }^{1}$ Stress and Cancer Laboratory, Equipe labelisée Ligue Nationale Contre le Cancer, Institut Curie, PSL Research University, 26, rue d'Ulm, F-75005 Paris, France. ${ }^{2}$ Inserm U830, Institut Curie, PSL Research University, 26, rue d'Ulm, F-75005 Paris, France. ${ }^{3}$ Department of Surgery, Institut Curie Hospital Group, 35 rue Dailly, 92210 Saint-Cloud, France. ${ }^{4}$ Inserm U1231, Chemotherapy and immune response, Center Georges François Leclerc, 1 rue du Professeur Marion, 21000 Dijon, France. ${ }^{5}$ Department of Pathology, Institut Curie Hospital Group, 35 rue Dailly, 92210 Saint-Cloud, France. ${ }^{6}$ Department of Pathology, Institut Curie Hospital Group, 26, rue d'Ulm, 75248 Paris, France. ${ }^{7}$ Inserm U900, Cancer et génome : bioinformatique, biostatistiques et épidémiologie, Institut Curie, 35 rue Dailly, 92210 Saint-Cloud, France. ${ }^{8}$ UR 7285, Risques cliniques et sécurité en santé des femmes et en santé périnatale, Versailles Saint Quentin en Yvelines University, 2 avenue de la source de la Bièvre, 78180 Montigny-le-Bretonneux, France.

Received: 3 January 2020 Accepted: 30 June 2020 Published online: 14 July 2020

\section{References}

1. Bray F, Ferlay J, Soerjomataram I, Siegel RL, Torre LA, Jemal A. Global cancer statistics 2018: GLOBOCAN estimates of incidence and mortality worldwide for 36 cancers in 185 countries. CA Cancer J Clin. 2018;68(6):394-424.

2. Perou CM, Sorlie T, Eisen MB, van de Rijn M, Jeffrey SS, Rees CA, Pollack JR, Ross DT, Johnsen H, Akslen LA, et al. Molecular portraits of human breast tumours. Nature. 2000;406(6797):747-52.

3. Sorlie T, Perou CM, Tibshirani R, Aas T, Geisler S, Johnsen H, Hastie T, Eisen $M B$, van de Rijn $M$, Jeffrey SS, et al. Gene expression patterns of breast carcinomas distinguish tumor subclasses with clinical implications. Proc Natl Acad Sci U S A. 2001;98(19):10869-74.

4. Sorlie T, Tibshirani R, Parker J, Hastie T, Marron JS, Nobel A, Deng S, Johnsen H, Pesich R, Geisler S, et al. Repeated observation of breast tumor subtypes in independent gene expression data sets. Proc Natl Acad Sci U S A. 2003; 100(14):8418-23.

5. Goldhirsch A, Winer EP, Coates AS, Gelber RD, Piccart-Gebhart M, Thurlimann B, Senn HJ. Personalizing the treatment of women with early breast cancer: highlights of the St Gallen International Expert Consensus on the Primary Therapy of Early Breast Cancer 2013. Ann Oncol. 2013;24(9): 2206-23.

6. Coates AS, Winer EP, Goldhirsch A, Gelber RD, Gnant M, Piccart-Gebhart M, Thurlimann B, Senn HJ. Tailoring therapies--improving the management of early breast cancer: St Gallen International Expert Consensus on the Primary Therapy of Early Breast Cancer 2015. Ann Oncol. 2015;26(8):1533-46.

7. Kasangian AA, Gherardi G, Biagioli E, Torri V, Moretti A, Bernardin E, Cordovana A, Farina G, Bramati A, Piva S, et al. The prognostic role of tumor size in early breast cancer in the era of molecular biology. PLoS One. 2017; 12(12):e0189127.

8. Giuliano AE, Connolly JL, Edge SB, Mittendorf EA, Rugo HS, Solin LJ, Weaver DL, Winchester DJ, Hortobagyi GN. Breast cancer-major changes in the American Joint Committee on Cancer eighth edition cancer staging manual. CA Cancer J Clin. 2017:67(4):290-303.

9. Hanrahan EO, Gonzalez-Angulo AM, Giordano SH, Rouzier R, Broglio KR, Hortobagyi GN, Valero V. Overall survival and cause-specific mortality of patients with stage T1a,bNOM0 breast carcinoma. J Clin Oncol. 2007;25(31): 4952-60.

10. Hanrahan EO, Valero V, Gonzalez-Angulo AM, Hortobagyi GN. Prognosis and management of patients with node-negative invasive breast carcinoma that is $1 \mathrm{~cm}$ or smaller in size (stage 1; T1a,bNOM0): a review of the literature. J Clin Oncol. 2006;24(13):2113-22.
11. Ignatov $T$, Eggemann $H$, Burger $E$, Costa SD, Ignatov A. Management of small T1a/b breast cancer by tumor subtype. Breast Cancer Res Treat. 2017; 163(1):111-8.

12. Prat A, Parker JS, Fan C, Perou CM. PAM50 assay and the three-gene model for identifying the major and clinically relevant molecular subtypes of breast cancer. Breast Cancer Res Treat. 2012;135(1):301-6.

13. Wallden B, Storhoff J, Nielsen T, Dowidar N, Schaper C, Ferree S, Liu S, Leung S, Geiss G, Snider J, et al. Development and verification of the PAM50-based Prosigna breast cancer gene signature assay. BMC Med Genet. 2015;8:54.

14. Ohnstad HO, Borgen E, Falk RS, Lien TG, Aaserud M, Sveli MAT, Kyte JA, Kristensen VN, Geitvik GA, Schlichting E, et al. Prognostic value of PAM50 and risk of recurrence score in patients with early-stage breast cancer with long-term follow-up. Breast Cancer Res. 2017;19(1):120.

15. Nielsen TO, Parker JS, Leung S, Voduc D, Ebbert M, Vickery T, Davies SR, Snider J, Stijleman IJ, Reed J, et al. A comparison of PAM50 intrinsic subtyping with immunohistochemistry and clinical prognostic factors in tamoxifen-treated estrogen receptor-positive breast cancer. Clin Cancer Res. 2010;16(21):5222-32

16. Pietras K, Ostman A. Hallmarks of cancer: interactions with the tumor stroma. Exp Cell Res. 2010;316(8):1324-31.

17. Toullec A, Gerald D, Despouy G, Bourachot B, Cardon M, Lefort S, Richardson M, Rigaill G, Parrini MC, Lucchesi $C$, et al. Oxidative stress promotes myofibroblast differentiation and tumour spreading. EMBO Mol Med. 2010;2(6):211-30.

18. Costa A, Scholer-Dahirel A, Mechta-Grigoriou F. The role of reactive oxygen species and metabolism on cancer cells and their microenvironment. Semin Cancer Biol. 2014:25:23-32.

19. Kalluri R. The biology and function of fibroblasts in cancer. Nat Rev Cancer. 2016;16(9):582-98.

20. Pure $E$, Blomberg R. Pro-tumorigenic roles of fibroblast activation protein in cancer: back to the basics. Oncogene. 2018;37(32):4343-57.

21. Ohlund D, Handly-Santana A, Biffi G, Elyada E, Almeida AS, Ponz-Sarvise M, Corbo V, Oni TE, Hearn SA, Lee EJ, et al. Distinct populations of inflammatory fibroblasts and myofibroblasts in pancreatic cancer. J Exp Med. 2017;214(3):579-96.

22. Costa A, Kieffer Y, Scholer-Dahirel A, Pelon F, Bourachot B, Cardon M, Sirven P, Magagna I, Fuhrmann L, Bernard C, et al. Fibroblast heterogeneity and immunosuppressive environment in human breast cancer. Cancer Cell. 2018;33(3):463-79 e410.

23. Givel AM, Kieffer $Y$, Scholer-Dahirel A, Sirven P, Cardon M, Pelon F, Magagna I, Gentric G, Costa A, Bonneau C, et al. miR200-regulated CXCL12beta promotes fibroblast heterogeneity and immunosuppression in ovarian cancers. Nat Commun. 2018:9(1):1056.

24. Su S, Chen J, Yao H, Liu J, Yu S, Lao L, Wang M, Luo M, Xing Y, Chen F, et al CD10(+)GPR77(+) cancer-associated fibroblasts promote cancer formation and chemoresistance by sustaining cancer stemness. Cell. 2018;172(4):84156 e816.

25. Desmedt C, Majjaj S, Kheddoumi N, Singhal SK, Haibe-Kains B, El Ouriaghli F, Chaboteaux C, Michiels S, Lallemand F, Journe F, et al. Characterization and clinical evaluation of CD10+ stroma cells in the breast cancer microenvironment. Clin Cancer Res. 2012;18(4):1004-14.

26. Avery D, Govindaraju P, Jacob M, Todd L, Monslow J, Pure E. Extracellular matrix directs phenotypic heterogeneity of activated fibroblasts. Matrix Biol. 2018:67:90-106.

27. Cremasco V, Astarita JL, Grauel AL, Keerthivasan S, Maclsaac K, Woodruff MC, Wu M, Spel L, Santoro S, Amoozgar Z, et al. FAP delineates heterogeneous and functionally divergent stromal cells in immune-excluded breast tumors. Cancer Immunol Res. 2018;6(12):1472-85.

28. Neuzillet C, Tijeras-Raballand A, Ragulan C, Cros J, Patil Y, Martinet M, Erkan M, Kleeff J, Wilson J, Apte M, et al. Inter- and intra-tumoural heterogeneity in cancer-associated fibroblasts of human pancreatic ductal adenocarcinoma. J Pathol. 2019;248(1):51-65.

29. Strell C, Paulsson J, Jin SB, Tobin NP, Mezheyeuski A, Roswall P, Mutgan C, Mitsios N, Johansson H, Wickberg SM, et al. Impact of Epithelial-Stromal Interactions on Peritumoral Fibroblasts in Ductal Carcinoma in Situ. J Natl Cancer Inst. 2019;111(9):983-995.

30. Li H, Courtois ET, Sengupta D, Tan Y, Chen KH, Goh JJ, Kong SL, Chua C, Hon LK, Tan WS, et al. Reference component analysis of single-cell transcriptomes elucidates cellular heterogeneity in human colorectal tumors. Nat Genet. 2017;49(5):708-18. 
31. Bartoschek M, Oskolkov N, Bocci M, Lovrot J, Larsson C, Sommarin M, Madsen CD, Lindgren D, Pekar G, Karlsson G, et al. Spatially and functionally distinct subclasses of breast cancer-associated fibroblasts revealed by single cell RNA sequencing. Nat Commun. 2018;9(1):5150.

32. Biffi G, Oni TE, Spielman B, Hao Y, Elyada E, Park Y, Preall J, Tuveson DA. IL1induced JAK/STAT signaling is antagonized by TGFbeta to shape CAF heterogeneity in pancreatic ductal adenocarcinoma. Cancer Discov. 2019; 9(2):282-301.

33. Feig C, Jones JO, Kraman M, Wells RJ, Deonarine A, Chan DS, Connell CM, Roberts EW, Zhao Q, Caballero OL, et al. Targeting CXCL12 from FAPexpressing carcinoma-associated fibroblasts synergizes with anti-PD-L1 immunotherapy in pancreatic cancer. Proc Natl Acad Sci U S A. 2013; 110(50):20212-7.

34. Wolff AC, Hammond ME, Hicks DG, Dowsett M, McShane LM, Allison KH, Allred DC, Bartlett JM, Bilous M, Fitzgibbons P, et al. Recommendations for human epidermal growth factor receptor 2 testing in breast cancer: American Society of Clinical Oncology/College of American Pathologists clinical practice guideline update. J Clin Oncol. 2013;31(31):3997-4013.

35. Salgado R, Denkert C, Demaria S, Sirtaine N, Klauschen F, Pruneri G, Wienert S, Van den Eynden G, Baehner FL, Penault-Llorca F, et al. The evaluation of tumor-infiltrating lymphocytes (TILS) in breast cancer: recommendations by an International TILs Working Group 2014. Ann Oncol. 2015;26(2):259-71.

36. Laenkholm AV, Jensen MB, Eriksen JO, Rasmussen BB, Knoop AS, Buckingham W, Ferree S, Schaper C, Nielsen TO, Haffner T et al: PAM50 risk of recurrence score predicts 10-year distant recurrence in a comprehensive Danish cohort of postmenopausal women allocated to 5 years of endocrine therapy for hormone receptor-positive early breast cancer. J Clin Oncol 2018:Jco2017746586.

37. Sestak I, Buus R, Cuzick J, Dubsky P, Kronenwett R, Denkert C, Ferree S, Sgroi D, Schnabel C, Baehner FL, et al. Comparison of the performance of 6 prognostic signatures for estrogen receptor-positive breast cancer: a secondary analysis of a randomized clinical trial. JAMA Oncol. 2018;4(4):545553.

38. Pelon F, Bourachot B, Kieffer Y, Magagna I, Mermet-Meillon F, Bonnet I, Costa A, Givel A, Attieh Y, Barbazan J, et al. Cancer-associated fibroblast heterogeneity in axillary lymph nodes drives metastases in breast cancer through complementary mechanisms. Nat Commun. 2020;1 1(1):404-24.

39. Early Breast Cancer Trialists' Collaborative G. Aromatase inhibitors versus tamoxifen in early breast cancer: patient-level meta-analysis of the randomised trials. Lancet. 2015:386(10001):1341-52.

40. Li Z, Yin S, Zhang L, Liu W, Chen B. Prognostic value of reduced E-cadherin expression in breast cancer: a meta-analysis. Oncotarget. 2017:8(10):16445-55.

41. Padmanaban V, Krol I, Suhail Y, Szczerba BM, Aceto N, Bader JS, Ewald AJ. Ecadherin is required for metastasis in multiple models of breast cancer. Nature. 2019;573(7774):439-44.

42. Corso G, Figueiredo J, De Angelis SP, Corso F, Girardi A, Pereira J, Seruca R, Bonanni B, Carneiro P, Pravettoni G, et al. E-cadherin deregulation in breast cancer. J Cell Mol Med. 2020;24(11):5930-5936.

43. Maeda M, Johnson KR, Wheelock MJ. Cadherin switching: essential for behavioral but not morphological changes during an epithelium-tomesenchyme transition. J Cell Sci. 2005;118(Pt 5):873-87.

44. Okazaki M, Takeshita S, Kawai S, Kikuno R, Tsujimura A, Kudo A, Amann E. Molecular cloning and characterization of OB-cadherin, a new member of cadherin family expressed in osteoblasts. J Biol Chem. 1994;269(16):12092-8.

45. Sarrio D, Rodriguez-Pinilla SM, Hardisson D, Cano A, Moreno-Bueno G, Palacios J. Epithelial-mesenchymal transition in breast cancer relates to the basal-like phenotype. Cancer Res. 2008;68(4):989-97.

46. Tamura D, Hiraga T, Myoui A, Yoshikawa H, Yoneda T. Cadherin-11-mediated interactions with bone marrow stromal/osteoblastic cells support selective colonization of breast cancer cells in bone. Int J Oncol. 2008;33(1):17-24

47. Assefnia S, Dakshanamurthy S, Guidry Auvil JM, Hampel C, Anastasiadis PZ, Kallakury B, Uren A, Foley DW, Brown ML, Shapiro L, et al. Cadherin-11 in poor prognosis malignancies and rheumatoid arthritis: common target, common therapies. Oncotarget. 2014;5(6):1458-74.

48. Buonomo OC, Caredda E, Portarena I, Vanni G, Orlandi A, Bagni C, Petrella G, Palombi L, Osaria P. New insights into the metastatic behavior after breast cancer surgery, according to well-established clinicopathological variables and molecular subtypes. PLoS One. 2017;12(9):e0184680.

49. Ignatov $A$, Eggemann $H$, Burger $E$, Ignatov T. Patterns of breast cancer relapse in accordance to biological subtype. J Cancer Res Clin Oncol. 2018; 144(7):1347-1355
50. Asgeirsson KS, Jonasson JG, Tryggvadottir L, Olafsdottir K, Sigurgeirsdottir JR, Ingvarsson S, Ogmundsdottir HM. Altered expression of E-cadherin in breast cancer. Patterns, mechanisms and clinical significance. Eur J Cancer. 2000; 36(9):1098-106.

51. Heimann R, Lan F, McBride R, Hellman S. Separating favorable from unfavorable prognostic markers in breast cancer: the role of E-cadherin. Cancer Res. 2000;60(2):298-304.

52. Berx G, Van Roy F. The E-cadherin/catenin complex: an important gatekeeper in breast cancer tumorigenesis and malignant progression. Breast Cancer Res. 2001;3(5):289-93.

53. Lim SC, Lee MS. Significance of E-cadherin/beta-catenin complex and cyclin D1 in breast cancer. Oncol Rep. 2002;9(5):915-28.

54. Pedersen KB, Nesland JM, Fodstad O, Maelandsmo GM. Expression of S100A4, E-cadherin, alpha- and beta-catenin in breast cancer biopsies. Br J Cancer. 2002:87(11):1281-6.

55. Rakha EA, Abd El Rehim D, Pinder SE, Lewis SA, Ellis IO: E-cadherin expression in invasive non-lobular carcinoma of the breast and its prognostic significance. Histopathology 2005, 46(6):685-693.

56. Gould Rothberg BE, Bracken MB. E-cadherin immunohistochemical expression as a prognostic factor in infiltrating ductal carcinoma of the breast: a systematic review and meta-analysis. Breast Cancer Res Treat. 2006; 100(2):139-48.

57. Howard EM, Lau SK, Lyles RH, Birdsong GG, Umbreit JN, Kochhar R. Expression of e-cadherin in high-risk breast cancer. J Cancer Res Clin Oncol. 2005;131(1):14-8.

58. Howard EM, Lau SK, Lyles RH, Birdsong GG, Tadros TS, Umbreit JN, Kochhar R. Correlation and expression of p53, HER-2, vascular endothelial growth factor (VEGF), and e-cadherin in a high-risk breast-cancer population. Int J Clin Oncol. 2004;9(3):154-60.

59. Querzoli P, Coradini D, Pedriali M, Boracchi P, Ambrogi F, Raimondi E, La Sorda R, Lattanzio R, Rinaldi R, Lunardi M, et al. An immunohistochemically positive E-cadherin status is not always predictive for a good prognosis in human breast cancer. Br J Cancer. 2010;103(12):1835-9.

60. Parker C, Rampaul RS, Pinder SE, Bell JA, Wencyk PM, Blamey RW, Nicholson $\mathrm{RI}$, Robertson JF. E-cadherin as a prognostic indicator in primary breast cancer. Br J Cancer. 2001;85(12):1958-63.

61. Onder T, Gupta PB, Mani SA, Yang J, Lander ES, Weinberg RA. Loss of Ecadherin promotes metastasis via multiple downstream transcriptional pathways. Cancer Res. 2008;68(10):3645-54.

62. Kantak SS, Kramer RH. E-cadherin regulates anchorage-independent growth and survival in oral squamous cell carcinoma cells. J Biol Chem. 1998; 273(27):16953-61.

63. Gillett CE, Miles DW, Ryder K, Skilton D, Liebman RD, Springall RJ, Barnes DM, Hanby AM. Retention of the expression of E-cadherin and catenins is associated with shorter survival in grade III ductal carcinoma of the breast. J Pathol. 2001;193(4):433-41.

64. Friedl $P$, Hegerfeldt $Y$, Tusch M. Collective cell migration in morphogenesis and cancer. Int J Dev Biol. 2004;48(5-6):441-9.

65. St Croix B, Kerbel RS. Cell adhesion and drug resistance in cancer. Curr Opin Oncol. 1997;9(6):549-56.

66. Mahmoud SM, Paish EC, Powe DG, Macmillan RD, Grainge MJ, Lee AH, Ellis 1O, Green AR. Tumor-infiltrating CD8+ lymphocytes predict clinical outcome in breast cancer. J Clin Oncol. 2011;29(15):1949-55.

67. Loi S, Sirtaine N, Piette F, Salgado R, Viale G, Van Eenoo F, Rouas G, Francis $P$, Crown JP, Hitre $E$, et al. Prognostic and predictive value of tumorinfiltrating lymphocytes in a phase III randomized adjuvant breast cancer trial in node-positive breast cancer comparing the addition of docetaxel to doxorubicin with doxorubicin-based chemotherapy: BIG 02-98. J Clin Oncol. 2013;31(7):860-7.

68. Loi S, Michiels S, Salgado R, Sirtaine N, Jose V, Fumagalli D, KellokumpuLehtinen PL, Bono P, Kataja V, Desmedt C, et al. Tumor infiltrating lymphocytes are prognostic in triple negative breast cancer and predictive for trastuzumab benefit in early breast cancer: results from the FinHER trial. Ann Oncol. 2014;25(8):1544-50.

69. Blok EJ, Engels CC, Dekker-Ensink G, Meershoek-Klein Kranenbarg E, Putter H, Smit V, Liefers GJ, Morden JP, Bliss JM, Coombes RC, et al. Exploration of tumour-infiltrating lymphocytes as a predictive biomarker for adjuvant endocrine therapy in early breast cancer. Breast Cancer Res Treat. 2018; 171(1):65-74.

70. Haragan A, Liebler DC, Das DM, Soper MD, Morrison RD, Slebos RJC, Ackermann BL, Fill JA, Schade AE, Gosney JR, et al. Accelerated instability 
testing reveals quantitative mass spectrometry overcomes specimen storage limitations associated with PD-L1 immunohistochemistry. Lab Investig. 2020;100(6):874-886.

71. Muenst S, Soysal SD, Gao F, Obermann EC, Oertli D, Gillanders WE. The presence of programmed death 1 (PD-1)-positive tumor-infiltrating lymphocytes is associated with poor prognosis in human breast cancer. Breast Cancer Res Treat. 2013;139(3):667-76.

72. Lee DW, Ryu HS, Jin MS, Lee KH, Suh KJ, Youk J, Kim JY, Min A, Lee HB, Moon $\mathrm{HG}$, et al. Immune recurrence score using 7 immunoregulatory protein expressions can predict recurrence in stage I-III breast cancer patients. Br J Cancer. 2019;121(3):230-236.

73. Yazhou C, Wenlv S, Weidong Z, Licun W. Clinicopathological significance of stromal myofibroblasts in invasive ductal carcinoma of the breast. Tumour Biol. 2004;25(5-6):290-5.

74. Surowiak P, Murawa D, Materna V, Maciejczyk A, Pudelko M, Ciesla S, Breborowicz J, Murawa P, Zabel M, Dietel M, et al. Occurence of stromal myofibroblasts in the invasive ductal breast cancer tissue is an unfavourable prognostic factor. Anticancer Res. 2007;27(4c):2917-24.

75. Yamashita M, Ogawa T, Zhang X, Hanamura N, Kashikura Y, Takamura M, Yoneda M, Shiraishi T. Role of stromal myofibroblasts in invasive breast cancer: stromal expression of alpha-smooth muscle actin correlates with worse clinical outcome. Breast Cancer. 2012;19(2):170-6.

76. Planche A, Bacac M, Provero P, Fusco C, Delorenzi M, Stehle JC, Stamenkovic I. Identification of prognostic molecular features in the reactive stroma of human breast and prostate cancer. PLoS One. 2011;6(5):e18640.

77. Ma XJ, Dahiya S, Richardson E, Erlander M, Sgroi DC. Gene expression profiling of the tumor microenvironment during breast cancer progression. Breast Cancer Res. 2009;11(1):R7.

78. Guo X, Zhu SX, Brunner AL, van de Rijn M, West RB. Next generation sequencing-based expression profiling identifies signatures from benign stromal proliferations that define stromal components of breast cancer. Breast Cancer Res. 2013;15(6):R117.

79. Frings O, Augsten M, Tobin NP, Carlson J, Paulsson J, Pena C, Olsson E, Veerla S, Bergh J, Ostman A, et al. Prognostic significance in breast cancer of a gene signature capturing stromal PDGF signaling. Am J Pathol. 2013;182(6):2037-47.

80. Finak G, Bertos N, Pepin F, Sadekova S, Souleimanova M, Zhao H, Chen H, Omeroglu G, Meterissian S, Omeroglu A, et al. Stromal gene expression predicts clinical outcome in breast cancer. Nat Med. 2008;14(5):518-27.

81. Chang HY, Nuyten DS, Sneddon JB, Hastie T, Tibshirani R, Sorlie T, Dai H, He $Y D$, van't Veer $L$, Bartelink $H$, et al. Robustness, scalability, and integration of a wound-response gene expression signature in predicting breast cancer survival. Proc Natl Acad Sci U S A. 2005;102(10):3738-43.

82. Bergamaschi A, Tagliabue E, Sorlie T, Naume B, Triulzi T, Orlandi R, Russnes HG, Nesland JM, Tammi R, Auvinen P, et al. Extracellular matrix signature identifies breast cancer subgroups with different clinical outcome. J Pathol. 2008;214(3):357-67.

83. Kraby MR, Kruger K, Opdahl S, Vatten LJ, Akslen LA, Bofin AM. Microvascular proliferation in luminal $A$ and basal-like breast cancer subtypes. J Clin Pathol. 2015;68(11):891-7.

84. Bear HD, Tang G, Rastogi P, Geyer CE Jr, Liu Q, Robidoux A, Baez-Diaz L, Brufsky AM, Mehta RS, Fehrenbacher L, et al. Neoadjuvant plus adjuvant bevacizumab in early breast cancer (NSABP B-40 [NRG Oncology]): secondary outcomes of a phase 3, randomised controlled trial. Lancet Oncol. 2015;16(9):1037-48.

85. Pishvaian MJ, Feltes CM, Thompson P, Bussemakers MJ, Schalken JA, Byers SW. Cadherin-11 is expressed in invasive breast cancer cell lines. Cancer Res. 1999;59(4):947-52.

86. Kawaguchi J, Takeshita S, Kashima T, Imai T, Machinami R, Kudo A. Expression and function of the splice variant of the human cadherin-11 gene in subordination to intact cadherin-11. J Bone Miner Res. 1999;14(5):764-75.

87. Feltes CM, Kudo A, Blaschuk O, Byers SW. An alternatively spliced cadherin-11 enhances human breast cancer cell invasion. Cancer Res. 2002;62(22):6688-97.

88. Lee DM, Kiener HP, Agarwal SK, Noss EH, Watts GF, Chisaka O, Takeichi M, Brenner MB. Cadherin-11 in synovial lining formation and pathology in arthritis. Science. 2007;315(5814):1006-10.

89. Sfikakis PP, Vlachogiannis NI, Christopoulos PF. Cadherin-11 as a therapeutic target in chronic, inflammatory rheumatic diseases. Clin Immunol. 2017;176: 107-13.

\section{Publisher's Note}

Springer Nature remains neutral with regard to jurisdictional claims in published maps and institutional affiliations.
Ready to submit your research? Choose BMC and benefit from:

- fast, convenient online submission

- thorough peer review by experienced researchers in your field

- rapid publication on acceptance

- support for research data, including large and complex data types

- gold Open Access which fosters wider collaboration and increased citations

- maximum visibility for your research: over $100 \mathrm{M}$ website views per year

At BMC, research is always in progress.

Learn more biomedcentral.com/submissions 